\title{
Criteria of Progress for Information Systems Design Theories
}

\author{
Stephan Aier, Christian Fischer
}

\begin{abstract}
According to Kuhn, science and progress are strongly interrelated. In this paper, we define criteria of progress for design theories. A broad analysis of the literature on information systems design science reveals that there is no consensus on the criteria of progress for design theories. We therefore analyze different concepts of progress for natural science theories. Based on well-founded criteria stemming from the philosophy of science and referring to natural science theories, we develop a set of criteria of progress for design theories. In summary, our analysis results in six criteria of progress for design theories: A design theory is partially progressive compared to another if it is ceteris paribus (1) more useful, (2) internally more consistent, (3) externally more consistent, (4) more general, (5) simpler, or (6) more fruitful of further research. Although the measurement of these criteria is not the focus of this paper, the problem of measurement cannot be totally neglected. We therefore discuss different methods for measuring the criteria based on different concepts of truth: the correspondence theory of truth, the coherence theory of truth, and the consensus theory of truth. We finally show the applicability of the criteria with an example.
\end{abstract}

Keywords: IS Design Science Research, Design Theory, Scientific Progress, Evaluation Criteria, Quality Criteria. 


\section{The Relevance of Progress}

Progress is regarded as one of the main aims of science; science can even be defined by progress. For instance, Kuhn (1970, p. 162) asks: "Does a field make progress because it is a science, or is it a science because it makes progress?" In view of its central importance for science, the concept of progress has been discussed in the philosophy of science since the $19^{\text {th }}$ century (Losee 2004 , p. 7-27). Although the discussion of scientific progress in the philosophy of science is multifarious, there is consensus on one point in the discourse: Scientific progress is a normative concept. A step from stage $A$ to $B$ constitutes progress if $B$ is better than $A$ with respect to some standards or criteria (Niiniluoto 2007). The object of discussion is the nature of such standards or criteria.

While such standards or criteria have been largely discussed for theories in natural science, they have not yet been widely discussed for Information Systems (IS) design theories, although many authors emphasize the importance of progress.

In IS Design Science Research ${ }^{1}$ (DSR), March and Smith (1995, p. 258) stress the role of progress when explaining artifact evaluation: "We evaluate artifacts to determine if we have made any progress. [...] Evaluation requires the development of metrics and the measurement of artifacts according to those metrics. [...] Lack of metrics and failure to measure artifact performance according to established criteria result in an inability to effectively judge research efforts."

We structure the research area on scientific progress in IS design theories into three research questions (RQ); they are listed in Table 1. In this paper, we focus on the first research question (RQ1) aimed at defining the concept of scientific progress in the context of IS DSR: "What criteria define scientific progress of one IS design theory in comparison with another?"

1 The relationship between IS design science research (DSR) and IS design theory development is discussed in the following section. 
Table 1: Research questions concerning the progress of design theories

\begin{tabular}{llll}
\hline No. & $\begin{array}{l}\text { Type of Research } \\
\text { Question }\end{array}$ & $\begin{array}{l}\text { Aim of Research } \\
\text { Question }\end{array}$ & Research Question \\
\hline (RQ1) & Ontological RQ & Definition & $\begin{array}{l}\text { What criteria define scientific progress of one } \\
\text { IS design theory in comparison with another? }\end{array}$ \\
(RQ2) & $\begin{array}{l}\text { Epistemological/ } \\
\text { Methodological RQ }\end{array}$ & Measurement & $\begin{array}{l}\text { How can scientific progress in IS design theo- } \\
\text { ries be determined? }\end{array}$ \\
(RQ3) & Praxeological RQ & Design & $\begin{array}{l}\text { How can scientific progress be achieved in IS } \\
\text { DSR? }\end{array}$ \\
\hline
\end{tabular}

In this paper, we do not set out to describe methods for determining progress in IS design theories. Nevertheless, as the definition of research criteria and their measurement are related, we briefly discuss the problem of measurement, too.

The paper is organized as follows: Firstly, we clarify the terminological and conceptual foundations of this paper. Many of the foundations of our argumentation are still under discussion. We therefore discuss and finally define some of the relevant concepts for the purpose of our paper. Secondly, we present related work. We start with related work inside the IS community. Our analysis reveals that a concept of progress for IS theories has yet to be developed systematically. We then broaden the scope of our literature review and briefly depict concepts of scientific progress as developed in the philosophy of science. This analysis results in a set of five criteria for scientific progress defined by Kuhn (1977). Thirdly, we transfer this Kuhnian set of criteria to IS design theories and explain it. Fourthly, we discuss epistemological and methodological perspectives for determining the fulfillment of the respective criteria while being fully aware that this is not the focus of our paper. Fifthly, we apply the criteria to an example: We compare Codd's (1970) design theory for relational databases with design theories for database types which were state-of-the-art at that ime. Sixthly and lastly, we draw a conclusion.

\section{Terminological and Conceptual Foundations}

IS DSR is still an emerging discipline (Kuechler et al. 2007). For this reason, a commonly accepted terminology has yet to be established. In order to use consistent terminology, we very briefly discuss key concepts and define them for the purpose of this paper. 


\section{Theories in Information Systems Research}

An information system (IS) "consists of not just the technology (hardware, software, data, networks) or the social settings (people, business processes, politics, economics, psychology, culture, organization, and management), but also the rich phenomena that emerge from the interactions between the two" (Lee 1999). Alter (2006) renders this view more precisely by defining an information system as a special kind of work system. A work system is "a system in which human participants and/or machines perform work using information, technology, and other resources to produce products and/or services for internal or external customers" (Alter 2006, p. 12). Alter then defines an information system as a "work system whose work practices are devoted to processing information, i.e. capturing, transmitting, storing, retrieving, manipulating, and displaying information" (Alter 2006, p. 18).

A special kind of outcome in this field of research is a design theory. A differentiation between design theories and other types of theories in IS has been provided by Walls et al. (1992). They differentiate between explanatory, predictive, and prescriptive theories, and define design theories as prescriptive theories. Gregor (2006) refines this classification and differentiates five types of theories: "(1) theory for analyzing, (2) theory for explaining, (3) theory for predicting, (4) theory for explaining and predicting, and (5) theory for design and action" (Gregor 2006). In sciences like physics, chemistry, or human biology, theories of Gregor's (2006) type (1) to (4) are developed; in applied sciences like engineering, pharmacy, or medicine, design theories are constructed (Gregor 2009). In the field of IS, theories of Gregor's (2006) type (1) to (4) are constructed by behavioral science, Gregor's theory of type (5) in IS design science research. ${ }^{2}$ In this paper, we focus on design theories, i.e. prescriptive theories for design and action. Most authors agree with Walls et al. (1992) and Gregor (2006) that a design is prescriptive (Goldkuhl 2004, Gregor and Jones 2007, Markus et al. 2002, Simon 1996, Walls et al. 2004). However, Gregor's (2006) classification is not undisputed. For instance, Venable (2006b) argues that design theories are predictive theories because they predict that they will be useful when applied.

2 For a detailed discussion of the relationship between IS DSR und IS design theory, we refer to the sub-section "Design Science Research and Design Theory". 
To simplify our terminology, we call theories of Gregor's (2006) types (1) to (4) traditional theories.

\section{Design Theories in Information Systems}

\section{Definition of a Design Theory}

A highly influential definition of design theory is given by Walls et al. (1992): “A design theory is a prescriptive theory based on theoretical underpinnings which says how a design process can be carried out in a way which is both effective and feasible." More specifically, Walls et al. (1992) characterize design theories by seven aspects which we have cited in Table 2.

Table 2: Characteristics of a design theory (Walls et al. 1992)

(1) Design theories must deal with goals as contingencies.

(2) A design theory can never involve pure explanation or prediction.

(3) Design theories are prescriptive.

(4) Design theories are composite theories which encompass kernel theories from natural science, social science and mathematics.

(5) While explanatory theories tell "what is", predictive theories tell "what will be", and normative theories tell "what should be", design theories tell "how to/because".

(6) Design theories show how explanatory, predictive, or normative theories can be put to practical use.

(7) Design theories are theories of procedural rationality.

Venable (2006a, 2006b) defines a design theory as a form of utility theory. He firstly defines a problem as a "perceived difference between what is and what should be"3 (Venable 2006a, p. 185, Venable 2006b, p. 15). "A utility theory then links some solution technology concept or group of concepts to the aspect(s) of the problem(s) that it/they address. [...] Any utility theory proposed should be precise about what problem(s) it addresses, what way it addresses the problem(s) [...] and what benefit would occur from applying the solution technology" (Venable 2006a, p. 185). Venable's conceptualization is shown in Figure 1.

3 Venable takes this definition from David Kroenke, but the citation is unknown. 


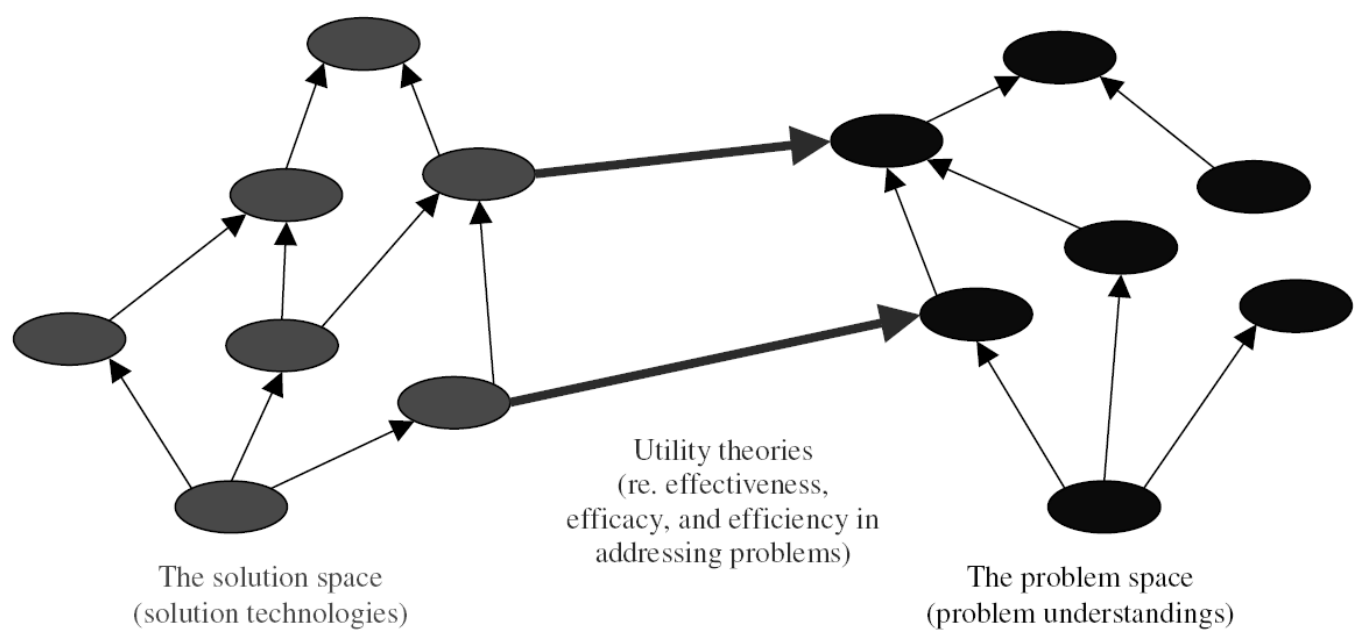

Figure 1: Components of utility theories (Venable 2006a, Figure 2, Venable 2006b, Figure 2)

\section{Componential Structure of a Design Theory}

A first definition of a componential structure of a design theory has already been described in the previous subsection: Venable (2006a, 2006b) defines a utility theory as a link between a solution space and a problem space.

A more detailed componential structure of a design theory is presented by Walls et al. (1992). The starting point for their definition is an analysis of components of traditional theory by Dubin (1978). Walls et al. (1992) then transfer Dubin's (1978) findings for traditional theories to design theories. They differentiate between two categories of elements of a design theory: design product and design process. The components of a design theory as defined by Walls et al. (1992) are shown in Table 3.

Table 3: Components of a design theory as defined by Walls et al. (1992)

\begin{tabular}{|c|c|c|}
\hline \multicolumn{3}{|c|}{ Design product } \\
\hline (1) & Meta-requirements & Describes the class of goals to which the theory applies. \\
\hline (2) & Meta-design & $\begin{array}{l}\text { Describes a class of artifacts hypothesized to meet the meta- } \\
\text { requirements. }\end{array}$ \\
\hline (3) & Kernel theories & $\begin{array}{l}\text { Theories from natural or social sciences governing design } \\
\text { requirements. }\end{array}$ \\
\hline (4) & Testable design product & $\begin{array}{l}\text { Used to test whether the meta-design satisfies the meta- } \\
\text { requirements hypotheses. }\end{array}$ \\
\hline \multicolumn{3}{|c|}{ Design process } \\
\hline (1) & Design method & A description of procedure(s) for artifact construction. \\
\hline (2) & Kernel theories & $\begin{array}{l}\text { Theories from natural or social sciences governing design } \\
\text { process itself. }\end{array}$ \\
\hline (3) & Testable design process & $\begin{array}{l}\text { Used to verify whether the design method results in an artifact } \\
\text { which is consistent with the meta-design. }\end{array}$ \\
\hline
\end{tabular}


Walls' et al. (1992) design theory components were extended by Gregor and Jones (2007). The latter define slightly different components of a design theory and do not differentiate between design process and design product; their componential structure of design theories is listed in Table 4. Gregor and Jones (2007) clearly demonstrate in their article that their definition of the components of a design theory is compatible with that of Walls et al. (1992) in many points. For the purposes of this paper, i.e. for defining criteria for the scientific progress of design theories, the definition by Gregor and Jones (2007) seems to be more apt. Therefore, we decided to mainly adopt the componential structure by Gregor and Jones (2007) as a definition for this paper.

Table 4: Components of a design theory according to Gregor and Jones (2007)

\begin{tabular}{|c|c|c|}
\hline \multicolumn{3}{|c|}{ Core components } \\
\hline (1) & $\begin{array}{l}\text { Purpose and scope } \\
\text { (causa finalis) }\end{array}$ & $\begin{array}{l}\text { "What the system is for," the set of meta-requirements or } \\
\text { goals that specifies the type of artifact to which the theory } \\
\text { applies and in conjunction also defines the scope, or bounda- } \\
\text { ries, of the theory. }\end{array}$ \\
\hline (2) & $\begin{array}{l}\text { Constructs } \\
\text { (causa materialis) }\end{array}$ & Representations of the entities of interest in the theory. \\
\hline (3) & $\begin{array}{l}\text { Principle of form and } \\
\text { function } \\
\text { (causa formalis) }\end{array}$ & $\begin{array}{l}\text { The abstract "blueprint" or architecture that describes an IS } \\
\text { artifact, either product or method/intervention. }\end{array}$ \\
\hline (4) & Artifact mutability & $\begin{array}{l}\text { The changes in state of the artifact anticipated in the theory, } \\
\text { that is, what degree of artifact change is encompassed by the } \\
\text { theory. }\end{array}$ \\
\hline (5) & Testable propositions & Truth statements about the design theory. \\
\hline (6) & Justificatory knowledge & $\begin{array}{l}\text { The underlying knowledge or theory from the natural or social } \\
\text { or design sciences that gives a basis and explanation for the } \\
\text { design (kernel theories). }\end{array}$ \\
\hline \multicolumn{3}{|c|}{ Additional components } \\
\hline (7) & $\begin{array}{l}\text { Principles of implemen- } \\
\text { tation (causa efficiens) }\end{array}$ & $\begin{array}{l}\text { A description of processes for implementing the theory (either } \\
\text { product or method) in specific contexts. }\end{array}$ \\
\hline (8) & Expository instantiation & $\begin{array}{l}\text { A physical implementation of the artifact that can assist in } \\
\text { representing the theory both as an expository device and for } \\
\text { purposes of testing. }\end{array}$ \\
\hline
\end{tabular}

\section{Unintended Side Effects of Design Theory Application}

Both the article by Walls et al. (1992) and that by Gregor and Jones (2006) are excellent. They are both well thought through, comprehensive (although when compared take a slightly different view), and thereby further the understanding of design theories and their componential structure. Nevertheless, for the purposes of our paper, we would like to discuss an aspect which, in our opinion, has only been 
touched on in the above mentioned papers: unintended side effects resulting from theory application. ${ }^{4}$

The application of a design theory might have more effects than those which are set forth in its purpose and scope. Such side effects can be positive as well as negative. March and Smith (1995, p. 254) already state: "A critical challenge in building an artifact is anticipating the potential side effects of its use, and insuring that unwanted side effects are avoided."

Bearing this in mind, there are two questions that arise, the one building on from the other:

(1) Should unintended side effects, whether positive or negative, be reflected in the componential structure of a design theory?

(2) If unintended side effects should be reflected in the componential structure of a design theory: To what component of a design theory do they belong?

To the best of our knowledge, neither Walls et al. (1992) nor Gregor and Jones (2007) clearly answer either of these two questions. Venable (2006a, pp. 4-5) mentions the importance of side effects; but although we assume that side effects are implicitly part of his definition of the componential structure of design theory (i.e. a link between a part of the solution space and a part of the problem space), he does not explicitly name side effects as a component of a design theory either. When answering the first question, we clearly plead in favor of reflecting side effects in the componential structure of design theory, at least for the purposes of this paper. Positive or negative side effects can increase or decrease the utility of a design theory. As we will argue later, the utility of a design theory is an important aspect for determining its progressivity. Therefore, this aspect cannot be neglected in this paper.

When answering the second question, we would like to discuss two positions: The first position holds that side effects are or should be incorporated in the definition of the meta-requirements for the purpose and scope of design theory; the second holds that a new component should be added to the componential structure of design theory called side effects.

Proponents of the first position, holding that side effects are part of the "purpose and scope" of the theory (respectively of its meta-requirements), can argue that

4 To be frank, we did not become aware of the issue of unintended side effects ourselves; one of the reviewers kindly drew our attention to this important aspect. 
side effects can only be referred to as such as long as one is unaware of them. Once a design theory has been applied and evaluated several times, originally unexpected effects become apparent. The purpose and scope of the theory then have to be adapted so that the side effects are taken into account.

Proponents of the second position, holding that a new component called side effects should be defined, can argue that the purpose and scope (respectively the meta-requirements) set forth the goal of the design theory. Unintended side effects, whether positive or negative, do not reflect the goal of the theory. They neither correspond to what the theory applier "requires" nor to his "purpose". Design theories are not applied for achieving these unintended effects, but for achieving the stated goals. Therefore, neither positive nor negative side effects should be part of the meta-requirements for the purpose and scope of the theory. Side effects are fundamentally different from other components of design theory; therefore, a new component type for design theories should be defined: (unintended) positive or negative side effects.

In this paper, we do not set out to answer the second question. Irrespective of the position the reader might take, we want to draw the reader's attention to this issue of unintended side effects and will refer to it later in the argumentation.

\section{Design Science Research and Design Theory}

In parallel with the discussion about design theories, a debate on the subject of "design science" has emerged. The popularity of the design science approach in IS increased when Hevner et al. (2004) published a seminal article on this approach. Since the First International Conference on Design Science Research in Information Systems and Technology (DESRIST) held in 2006, the IS DSR community meets annually.

According to March and Smith (1995), design science research is aimed at developing useful IS artifacts, namely constructs, models, methods, and instantiations. Moreover, March and Smith (1995, p. 258) propose four subsequent phases in a research process whereby they attribute the first two phases to design science research: (1) build, (2) evaluate, (3) theorize, and (4) justify. With regard to theory building and justification, March and Smith (1995, p. 259) state that "[s]uch research applies natural science methods to IT artifacts". Hence, they exclude theory building and justification from the core process of IS DSR. Newer IS DSR pro- 
cesses agree with March and Smith (1995) on this point (cf. the literature analysis by Peffers et al. 2007, table 1), i.e. they do not include theory building and justification. The rift between the two approaches, i.e. IS design theory building and IS DSR, did not become any smaller when Hevner et al. (2004) published their article on IS DSR. Despite having highly appreciated this article, Walls et al. (2004, p. 44) explain with regard to Hevner et al. (2004): "To our chagrin, the authors were unaware of our ISDT [Information Systems Design Theory] until it was drawn to their attention late in the cycle."

However, Walls et al. (2004) do not see their view of design theory as conflicting with the design science perspective: "Using observation and experimentation, the natural science process extracts data from the environment to create theories that become part of the knowledge base of the scientific community. The design science process selects from among these theories and combines them with goals of actors in the environment to create new design theories" (Walls et al. 2004, p. 48). Hence, for Walls et al. (2004), theories are created in a DSR process by "combining" what we call traditional theories with goals of actors. In fact, not only Walls et al. (2004) argue that IS DSR should theorize, but so does Venable (2006b) in an excellent article on the role of theory and theorizing in IS DSR. After analyzing the development of IS design theory building and that of IS DSR, Venable (2006b) clearly pleads for theorizing in IS DSR in line with Gregor and Jones (2007).

In this paper, we also argue that the aim of IS DSR should be to develop prescriptive theories, i.e. design theories. We thereby recognize that both approaches, IS design theory building and IS DSR, share a common fundament (e.g. Simon 1996) and have very similar outputs, i.e. they are aimed at showing "how to" solve a relevant problem. We agree with Gregor and Jones (2007, p. 320) "that 'constructs, models and methods' are all one type of thing and can be equated to theory or components of theory, while instantiations are a different type of thing altogether." As the two approaches IS design theory building and IS DSR are fundamentally related, our work is inspired by both of them in the following sections.

\section{Related Work}

Before proposing a set of criteria of progress for IS design theories, we review relevant literature. In the first part of this section, we review literature in the field 
of information systems. This review will show that, to the best of our knowledge, no author inside information systems has systematically developed a set of criteria of progress for IS design theories. Therefore, in the second part of this section, we broaden the scope of our review and include authors referring to traditional theories.

\section{Related Work to Criteria of Progress for Information Systems Design Theories}

We found only little work in which criteria of progress for IS design theories have been developed. Nevertheless, in the previous section, we have discussed the relationship between IS DSR and IS design theories. As the two concepts are strongly interrelated, we considered literature referring to IS design theories as well as literature referring to IS DSR in our review and identified two areas of related work: The first area of related work is about concepts of progress referring to IS design theory and IS DSR. Only few authors use the word "progress"; we show how they used it and how they understand progress.

The second area of related work is about evaluation criteria for IS design research artifacts. (Unfortunately, we did not find evaluation criteria explicitly for IS design theories.) As we will show in the first area of related work, according to March and Smith (1995), the purpose of artifact evaluation is to show that progress was achieved. Evaluation criteria therefore correspond to criteria of progress.

Concepts of Progress for Information Systems Design Theories and in Information Systems Design Science Research

In our literature review on concepts of progress, we identified two notions of progress.

Firstly, according to Walls et al. (1992, p. 41), a good design theory must be subject to empirical refutation. The argumentation by Walls et al. refers to Nagel (1961) who is known as a logical positivist. Empirical refutation of a theory leads to its falsification. According to Critical Rationalism (e.g., Popper 1963, Popper 1973), the falsification of theories and the subsequent search for new theories leads to scientific progress. March and Smith (1995, p. 254) similarly state that 
"[p]rogress is achieved in design science when existing technologies are replaced by more effective ones".

Secondly, Markus et al. (2002, p. 207) state that their "conceptualization is only as good as its implications for further research.” Also Hevner et al. (2004, p. 81) write that contributions in IS design science are assessed, for instance, "as they add to the content of the knowledge base for further research."

Criteria for "good" IS DSR artifacts are discussed in the context of the evaluation of an artifact that has been constructed. In this discussion, some authors highlight the interdependencies between an artifact and its environment. Hevner et al. (2004, p. 85) remark that new technology or a changing environment can make criteria assumed in prior research invalid. March and Smith (1995, p. 254) point out that "[s]ignificant difficulties in design science result from the fact that artifact performance is related to the environment in which it operates" and conclude that evaluation criteria for an artifact must be determined to correspond with its particular environment. Also, Gregor and Jones (2007, p. 327) are aware of the interdependence between artifact and environment, and list testable propositions as a component of design theories. The testable propositions are intended to allow the researcher to formulate (testable) quality factors adapted to the artifact as well as to its environment.

\section{Evaluation Criteria for Information Systems Design Science Research Arti- facts}

In literature, we did not find any set of evaluation criteria for IS design theories. Nonetheless, evaluation criteria for IS DSR artifacts should be strongly related to those for IS design theories. We therefore shortly show the result of our literature review on evaluation criteria for IS DSR artifacts.

The evaluation criteria for IS DSR artifacts mentioned in literature are often specific to a particular artifact type. For instance, March and Smith (1995) list criteria for constructs, models, methods, and instantiations. Moreover, a variety of quality criteria is developed by authors referring to one specific artifact type. In this paper, we focus on criteria that are independent of any particular artifact type and refer to design theories. Such criteria can be clustered into two sets:

The first set of evaluation criteria refers to the utility of a design theory. March and Smith (1995, p. 258) explain: "We evaluate artifacts to determine if we made 
any progress. The basic question is, how well does it work?" Design theories are sometimes also called "utility theories" (Venable 2006b); their usefulness for practitioners is emphasized by most authors as a main characteristic of design theories (Hevner et al. 2004). Criteria like quality and efficacy are related to the usefulness of a design theory (Hevner et al. 2004, p. 85).

The second set of criteria refers to a notion of aesthetics. Some authors even discuss IS research as being an art rather than a science; Lee (1991), for instance, proposes architecture as a reference discipline for IS. Hevner et al. (2004, p. 8687 get to the crux of aesthetical aspects in IS design science: "Good designers bring an element of style to their work (Norman 1988). Thus, we posit that design evaluation should include an assessment of the artifact's style. The measurement of style lies in the realm of human perception and taste. In other words, we know good style when we see it." Gelernter (1998) describes style "as a marriage between simplicity and power that drives innovation in science and technology" (Hevner et al. 2004, p. 87). Besides simplicity, the criteria "coherency" and "consistency" have stylistic elements. The legitimacy of such criteria referring to style is debatable as art and science fundamentally differ from each other.

We did not find any article that proposes a set of criteria that are independent of artifact type; nevertheless, to the best of our knowledge, the most comprehensive set of evaluation criteria for IS design science research artifacts is proposed by March and Smith (1995). We list their criteria depending on different artifact types in Table 5. March and Smith's (1995) evaluation criteria for constructs are completeness, ease of use, elegance, simplicity, and understandability; for models they are completeness, fidelity with real-world phenomena, internal consistency, level of detail, and robustness; for methods ease of use, efficiency, generality, and operationality; and for instantiations effectiveness, efficiency, and the artifact's impact on the environment and its users. These criteria are certainly well thought out; nevertheless, they suffer from two fundamental weaknesses: Firstly, very little justification for the criteria is provided; secondly, the criteria all refer to different types of IS DSR artifacts and lack the holistic view adopted by a design theory. We will therefore propose a set of criteria whose justification is based on the long tradition of the philosophy of science. Nonetheless, when discussing “our" criteria of progress for IS design theories, we will use the criteria proposed 
by March and Smith (1995) in order to evaluate whether our proposition corresponds to that of March and Smith (1995) in some way.

Table 5: Evaluation criteria for IS DSR artifacts of different types (March and Smith 1995)

\begin{tabular}{|c|c|c|c|c|}
\hline & 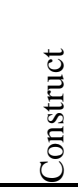 & $\begin{array}{l}\overline{0} \\
\overline{0} \\
\Sigma\end{array}$ & 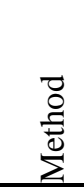 & 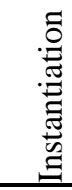 \\
\hline Completeness & $\mathrm{X}$ & $\mathrm{X}$ & & \\
\hline Ease of use & $\mathrm{X}$ & & $\mathrm{X}$ & \\
\hline Effectiveness & & & & $\mathrm{X}$ \\
\hline Efficiency & & & $\mathrm{X}$ & $\mathrm{X}$ \\
\hline Elegance & $X$ & & & \\
\hline Fidelity with real world phenomena & & $\mathrm{X}$ & & \\
\hline Generality & & & $X$ & \\
\hline Impact on the environment and on the artifacts' users & & & & $\mathrm{X}$ \\
\hline Internal consistency & & $\mathrm{X}$ & & \\
\hline Level of detail & & $\mathrm{X}$ & & \\
\hline Operationality & & & $\mathrm{X}$ & \\
\hline Robustness & & $\mathrm{X}$ & & \\
\hline Simplicity & $\mathrm{X}$ & & & \\
\hline Understandability & $\mathrm{X}$ & & & \\
\hline
\end{tabular}

\section{Conclusion}

Our review of IS design science literature reveals that few authors explicitly write about evaluation criteria. Some authors list evaluation criteria for IS design research artifacts. But no author develops and justifies a consistent set of criteria of progress for IS design theories. In view of these deficiencies, as already indicated in the introduction, we will go back to the discussion of scientific progress in the philosophy of science in order to systematically develop a consistent set of criteria for scientific progress in design theories.

\section{Related Work to Criteria of Progress for Traditional Theories}

The philosophy of science has a long tradition in discussing scientific progress. We will not be able to summarize this discussion within the limits of this paper. Instead, we propose a set of five criteria by Kuhn and try to adumbrate that the criteria do not contradict the notion of progress in three major schools in philosophy of science, i.e. Logical Empiricism, Critical Rationalism, and the Historical View by Kuhn and Feyerabend. 
Kuhn (1977, p. 321) proposes a set of five criteria of progress for traditional theories: accuracy, consistency, broad scope, simplicity, and their fruitfulness of new research findings. These five criteria (K1 to K5) are described in Table 6. Kuhn himself adds two critical remarks. Firstly, the criteria are individually imprecise: Individuals might differ about their application to concrete cases. Secondly, "when deployed together, they repeatedly prove to conflict with one another" (Kuhn 1977, p. 322).

Table 6.Criteria for scientific progress of traditional theories by Kuhn (1977, p. 321)

\begin{tabular}{|c|c|c|}
\hline No. & Criterion & Description \\
\hline $\mathrm{K} 1$ & Accuracy & $\begin{array}{l}\text { "[A] theory should be accurate: within its domain, that is, conse- } \\
\text { quences deducible from a theory should be in demonstrated agree- } \\
\text { ment with the results of existing experiments and observations" } \\
\text { (Kuhn } 1977, \text { p. } 321 \text { ). }\end{array}$ \\
\hline $\mathrm{K} 2$ & $\begin{array}{l}\text { Internal \& Exter- } \\
\text { nal Consistency }\end{array}$ & $\begin{array}{l}\text { "[A] theory should be consistent, not only internally or with itself, } \\
\text { but also with other currently accepted theories applicable to related } \\
\text { aspects of nature" (Kuhn 1977, p. 321). }\end{array}$ \\
\hline K3 & Broad Scope & $\begin{array}{l}\text { A theory "should have broad scope: in particular, a theory's conse- } \\
\text { quences should extend far beyond the particular observations, laws, } \\
\text { or subtheories it was initially designed to explain" (Kuhn 1977, p. } \\
321 \text { ). }\end{array}$ \\
\hline K4 & Simplicity & $\begin{array}{l}\text { A theory "should be simple, bringing order to phenomena that in its } \\
\text { absence would be individually isolated and, as a set, confused" } \\
\text { (Kuhn 1977, p. } 321 \text { ). }\end{array}$ \\
\hline K5 & $\begin{array}{l}\text { Fruitfulness of } \\
\text { New Research } \\
\text { Findings }\end{array}$ & $\begin{array}{l}\text { "[A] theory should be fruitful of new research findings: it should, } \\
\text { that is, disclose new phenomena or previously unnoted relationships } \\
\text { among those already known" (Kuhn 1977, p. } 321 \text { ). Kuhn classifies } \\
\text { fruitfulness of new research findings as a "somewhat less standard } \\
\text { item, but one of special importance to actual scientific decisions" } \\
\text { (Kuhn 1977, p. } 321 \text { ). }\end{array}$ \\
\hline
\end{tabular}

In the following three sub-sections, we show concept of progress of three influential schools in philosophy of science: Logical Empiricism, Critical Rationlism, and the Historical View by Kuhn.

\section{Logical Empiricism}

Logical Empiricism developed a notion of scientific progress mainly based on the idea of extending the scope of a theory (cf. K3). 


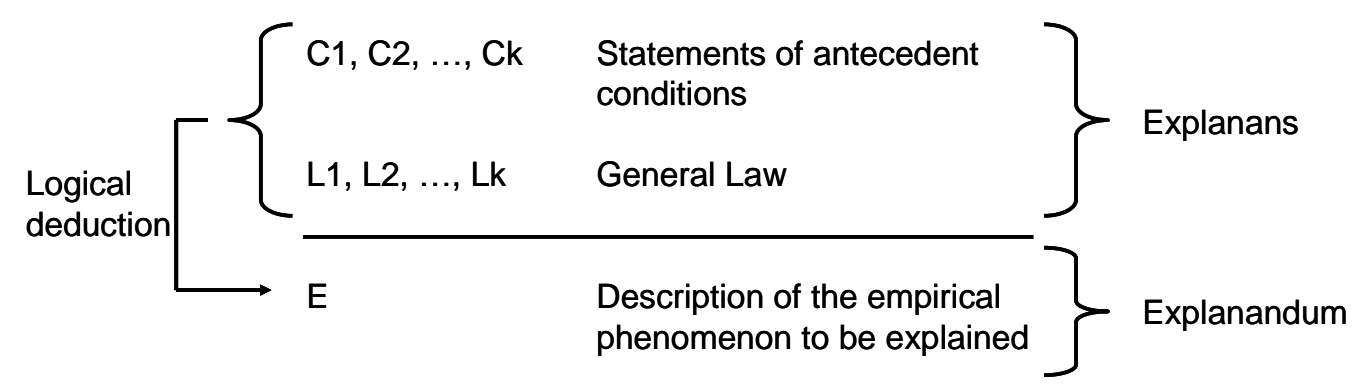

Figure 2. Deductive-nomological model for scientific explanations (Hempel and Oppenheim 1948, p. 138)

The emergence of Logical Empiricism is often said to be the beginning of the modern philosophy of science. It was mainly developed by the philosophers of the Vienna Circle from the 1920s onwards. The seminal contributions of Logical Empiricism to the philosophy of science in general, and to the subject of scientific progress in particular, were a starting point for the discussion by many philosophers later on. For the conceptualization of science by Logical Empiricism, the deductive-nomological model for scientific explanations by Hempel and Oppenheim (1948) is central. A scientific explanation consists of an explanans and an explanandum logically deduced from the explanans. The explanans consists of at least one statement of antecedent conditions and at least one general law. The explanandum is a description of the empirical phenomenon to be explained, cf. Figure 2.

The scientific explanation by Hempel and Oppenheim can explain concrete phenomena, but also general laws. Hempel (1962, p. 100-101) gives the following example from history of science: “[T]he uniformity expressed by Galileo's law for free fall can be explained by deduction from the general laws of mechanics and Newton's law of gravitation, in conjunction with statements specifying the mass and radius of the earth." The concept of scientific progress in Logical Empiricism is based precisely on that deduction of a less comprehensive theory from another which is more comprehensive: The more comprehensive theory is then progressive compared with the less comprehensive one. This concept is based on the assumption of a continuity of scientific knowledge, such that proceeding theories logically entail their predecessors.

The notion of progress in Logical Empiricism is covered by the set of five Kuhnian criteria as Kuhn considers a theory with a broader scope to be more progressive than another which is less broad in scope. The strong assumption of a 
continuity of science which is today denied by many philosophers of science is intentionally omitted by Kuhn.

\section{Critical Rationalism}

Critical Rationalism mainly developed by Karl Popper emphasizes the content of a theory and its verisimilitude. This notion of progress is covered by the Kuhnian criteria of accuracy (cf. K1) and broad scope (K3).

In contrast with Logical Empiricism, Popper does not emphasize continuity in science, but contradiction. For Popper, two theories which explain the same phenomenon differently will conflict with each other until one of them is falsified. The weakness of this concept is that it fails, in a first step, to distinguish more progressive theories from less progressive ones (Dilworth 2007, p. 26). As a concept of scientific progress is crucial for each concept of science, Popper claims two criteria that make one theory more progressive in comparison with another: its content and its verisimilitude.

Popper's "study of the content of a theory [...] was based on the simple and obvious idea that the informative content of the conjunction, ab, [...] will always be greater than, or at least equal to, that of any of its components. Let $a$ be the statement 'It will rain on Friday'; $b$ the statement 'It will be fine on Saturday'; and $a b$ the statement 'It will rain on Friday and it will be fine on Saturday': it is then obvious that the informative content of this last statement, the conjunction $a b$, will exceed that of its component $a$ and also that of its component $b$ " (Popper 1963 217-218). For instance, according to Popper, Keppler's or Galileo's theory is logically less strong and testable compared with that of Newton; therefore, Newton's theory has a richer content and is progressive in relation to that of Keppler or Galileo. Moreover, the content of a theory is inverse to its probability. Obviously, the probability of $a b$ is less than the probability of $a$ or the probability of $b$. Consequently, a less probable theory has a greater content and is therefore ceteris paribus (c. p.) progressive (Popper 1963, p. 218).

The second Popperian criterion for scientific progress, the verisimilitude of a theory, can be described by its nearness to truth. According to Popper, the truth of a theory cannot be attained, but rather approached. A theory $a$ is closer to truth than a theory $b$ if $a$ has more true consequences and less false ones than $b$ (Niiniluoto 2007). 
The criteria corresponding to the Popperian notion of content of a theory are the Kuhnian criteria of accuracy (cf. K1) and a broad scope (cf. K3). The verisimilitude corresponds to the accuracy of the theory.

\section{Kuhn's Historical View}

Kuhn (1970), in contrast with Logical Empiricism and Critical Rationalism, does not state how science ought to be, but develops a descriptive approach by analyzing the history of science, i.e. he describes how science factually is. Feyerabend, in particular, seizes on many suggestions by Kuhn and strongly criticizes Popper's emphasis on falsification, arguing that falsification has almost never been the reason for rejecting a theory (Feyerabend 1989, p. 250-259).

Kuhn mainly differentiates two phases of a science: normal science and scientific revolution. He (1970, p. 35-42) describes normal science as "puzzle solving" whereas revolutionarily new outcomes are characteristic for a phase of scientific revolution. Kuhn's (1970) and Feyerabend's (1962) conception of scientific progress is strongly marked by their incommensurability thesis. In their view, a theory is always evaluated by comparing it to a paradigm. Therefore, the standards of theory evaluation are not permanent because paradigms change; they are not theory-independent because they involve a comparison with a (paradigm) theory; and they are not based on rules because they involve perceived relations of similarity (Bird 2008). Consequently, when two theories are based on two different paradigms it is very difficult - if not impossible - to compare them. Despite being skeptical of theory comparisons, Kuhn (1977) proposes the set of criteria of scientific progress presented in Table 6 above.

\section{Conclusion}

In conclusion, we can state that Kuhn's five criteria by are able to cover the notions of scientific progress in Logical Empiricism and Critical Rationalism. Therefore, we will proceed on the basis of Kuhn's criteria, while systematically adapting them to design theories.

\section{Criteria of Progress for Design Theories}

The aim of our research is to identify of progress for design theories. For this purpose, we first analyzed IS literature and found a heterogeneous set of criteria that 
have been defined by different authors and have not been systematically developed and justified. In order to define a more homogenous set of criteria for evaluating IS design theories, we analyzed different concepts of scientific progress referring to traditional theories. We finally showed that a set of five criteria defined by Kuhn is able to cover the different notions of scientific progress in Logical Positivism and Critical Rationalism.

We now aim to transfer these criteria to IS design theories. Our methodological approach is very similar to that of Walls et al. (1992) who adapted the structure of traditional theories to the special characteristics of design theories. In line with the approach of Walls et al. (1992), our transfer will rely on the special characteristics of design theories.

This section starts with a short technical instruction defining when two design theories compete. The following six sub-sections are structured along the five Kuhnian criteria of progress in traditional theories. For reasons of practicality, the Kuhnian criterion (K2), i.e. internal and external consistency, is split into two criteria: internal consistency $(\mathrm{K} 2 \mathrm{a})$ and external consistency $(\mathrm{K} 2 \mathrm{~b})$. After that, the criteria for comparing two design theories are summarized. Finally, the problem of two conflicting criteria is explained and ceteris paribus rules for partial progress are proposed as a solution.

\section{What Makes Two Design Theories Competitive?}

Kuhn (1977) defined the set of five criteria of "good" scientific theories described above. The starting point for the definition of these criteria was the problem of two conflicting theories. If two theories are meant to explain the same phenomenon the question will arise: "Which of the two theories is better?" As an example, Kuhn (1977) mentions the discussion of the geocentric and heliocentric world views. In the $2^{\text {nd }}$ century AC, Ptolemy defined a geocentric model for explaining movements of orbs. Around 1,300 years later, Copernicus defined a heliocentric model describing the same phenomena in a completely different way. Now the question arises: "Which of the two models is better?"

The same question arises when a new design theory is constructed. For example, until Codd (1970) developed his design theory for adding, manipulating, and selecting data based on a relational model, databases had been constructed according to different design theories. Codd's design theory concurred, for instance, with 
design theories for hierarchical databases. (Although design theories for hierarchical database systems might not have been explicated, they were nevertheless applied and therefore existed.) The question then arose: Which design theory is better: Codd's theory based on a relational model or other design theories whose application results in a hierarchical database system.

Both the design theories for relational database systems and those for hierarchical database systems are in competition because they refer (at least partly) to the same purpose and scope, i.e. both design theories are intended as a guide to developers who build systems for storing, changing, and retrieving data. A necessary condition for the comparability of two design theories is that both have the same purpose and scope. If two design theories only partially have the same purpose and scope, then only those parts of the design theory which cover identical purpose and scope will be comparable.

In the following six subsections, the applicability of the six criteria defined by Kuhn will be discussed (and, if necessary, they will be adapted to the special requirements of design theories).

\section{Accuracy (K1)}

Kuhn's (1977) first criterion for a "good" traditional theory is accuracy. It is composed of the explanatory and predictive power of the theory. Design theories are not aimed at explaining or predicting, but at being useful; they are therefore a special kind of "utility theory" (Venable 2006b). Walls et al. (1992, p. 14) have already stated that " $[\mathrm{g}]$ oal orientation is the key element required in a design theory which is missing in a theory as defined by Dubin, Nagel, Popper, or Kuhn", i.e. a traditional theory. We therefore replace the Kuhnian criterion of accuracy for traditional theories by utility for design theories.

A design theory is useful if it fulfills its purpose and if the purpose is useful itself. A "useful purpose" is a purpose that is relevant for the user of the design theory. Hevner et al. (2004, table 1) state that "[t]he objective of design science is to develop technology-based solutions to important and relevant business problems". Therefore, Rossi and Sein (2003) propose beginning the design research process by identifying the need for a solution. If the need for a design theory is justified, the researcher can concentrate on evaluating how well the design theory fulfills its purpose. Of course, in this evaluation, tangible as well as intangible benefits 
should be considered. For evaluating the utility of a design theory, Walls et al. (1992) propose "testable design product hypotheses" in the first part of their design theory dealing with the design product and "testable design process hypotheses" in the second part of their design theory dealing with the design process. Testable design product hypotheses are used to verify whether the meta-design satisfies the meta-requirements; testable design process hypotheses to verify whether or not the design method results in an artifact which is consistent with the meta-design (Walls et al. 1992, p. 43). Gregor and Jones (2007) also stipulate the formulation of "testable propositions" for a design theory and state the same reasons as Walls et al. (1992) for doing so. These propositions are usually tested by instantiation, e.g. by constructing a system or by implementing a method.

\section{Three Different Kinds of Utility}

There are three different criteria for measuring how "well" a design theory fulfills its purpose and scope. Firstly, utility can refer to the absolute output (gross utility); secondly, it can refer to a difference between output and input (net utility); and, thirdly, it can refer to a quotient of output and input (efficiency).

Gross utility is the absolute output of a design theory whereby the input (i.e. costs of constructions and use) is not considered at all. In engineering sciences, a research project might be aimed at building a train which is faster than any train that ever existed, or at building a spacecraft which can reach places that are further away than any places that have ever been reached. In information systems, similar design research goals can be formulated; for example, a decision support system capable of delivering certain information faster than any other decision support system, or a method for post-merger IT integration with a higher success rate than any other post-merger IT integration method that has ever existed.

Nevertheless, in a business context, costs will be relevant in most cases. The difference between output (i.e. gross utility) and input (i.e. costs) is the net utility. Two types of costs can be differentiated: firstly costs for constructing an artifact by applying a design theory, and secondly costs for using an artifact resulting from the application of a design theory. Costs for using an artifact comprise costs for adapting the artifact to the concrete environment ("customizing") as well as for deploying, operating and deconstructing it. In the evaluation phase of a design research process, only these latter costs for using the design research artifact are 
relevant; the costs for constructing the artifact can be considered as sunk costs. Gross utility is a useful criterion for measuring the utility of a design theory whose artifact is used only once or a few times.

If an artifact resulting from a design theory is used very often, its efficiency might be the best criterion for measuring its utility. Efficiency is defined as a quotient of output (gross utility) and input (costs). If, for instance, two design theories for designing an operational customer relationship management process concur, the more useful of the two might be the most efficient one. If the usage of the first reference model provides a gross utility of 6 at costs of 3 and the usage of the second one a gross utility of 3 at costs of 1 , the second one should be chosen although its gross utility is smaller.

\section{Side Effects}

Besides the purpose and scope of the theory that is directly explicated, side effects have to be considered when comparing the utility of two design theories. We discussed at length the problem of side effects and their representation in the componential structure of design theories further above in this paper.

Needless to say, a design theory $A$ with less strong negative side effects is ceteris paribus progressive compared to a design theory $B$ with stronger negative side effects.

As far as positive side effects are concerned, it is disputable whether a design theory should be called progressive just because of its stronger positive side effects. Of course, positive side effects increase the utility of the theory. Nevertheless, the utility of a design theory should be determined with respect to its goals. If a design theory fulfills more purposes than stated, its definition of purpose and scope should be broadened. As we will see later, this also constitutes progress according to our argumentation.

\section{Utility Scales and Incommensurability}

When comparing two design theories, their utility must be measured on the same scale; it must be at least an ordinal scale. For the criterion of net utility, both gross utility and costs of the two design theories must be measured at least with the same interval scale; for the criterion of efficiency, they must be measured on the same ratio scale, e.g. in a monetary unit. 
Needless to say, a design theory might have more than one testable proposition, and these different testable propositions might refer to different aspects of its purpose and scope. It is possible that these propositions referring to different aspects of utility are measured on different scales which are incommensurable. We want to show two exemplary possibilities for dealing with this problem:

Firstly, we refer to the ceteris paribus clause for different criteria of progress we have discussed in the previous sub-section. We argued that a design theory $A$ is progressive compared with another design theory $B$ if $A$ fulfills at least one of the criteria better than $B$ whilst the fulfillment of the other criteria remains equal. Of course, this rule can also to be applied if two design theories are compared with respect to more than one utility measure.

Secondly, the different utility measures on different scales can be translated to the same scale, for instance a scale based on a monetary unit. The two can then be compared. Needless to say, in most cases, such a translation will not be easy. Information will often get lost and/or additional information will be necessary in such a "translation". In the discussion section of this paper, we will mention different approaches to measurement. While based on different concepts of truth, some of these approaches should nevertheless be applicable for translating between different scales.

\section{Internal Consistency (K2a)}

Kuhn claims a superior traditional theory to be internally consistent. An internally contradictory theory can neither explain nor predict phenomena correctly over its entire scope.

Internal consistency is also a relevant criterion for good information systems design theory. If a design theory is internally contradictory it cannot fulfill its purpose over its entire scope. An example of a design theory criticized for being internally inconsistent is the Function Point Method ${ }^{5}$ used for estimating the effort of an IT project (Albrecht 1979). For instance, Kitchenham and Kansalas (1993)

5 We consider the function point method to be a design theory. Although it does not directly refer to the design of a computer system, it refers to the design of an IS artifact. At the beginning of this paper, we adopted the IS definition by Alter (2006, p. 12) who defines an information system as a specific "work system whose work practices are devoted to processing information, i.e. capturing, transmitting, storing, retrieving, manipulating, and displaying information." Taking this definition, a method for estimating the costs of an IS project is clearly part of the information system. Ergo, the function point method is a (theoretical) approach saying how to design (a part of) an information system. 
remark that the method is inconsistent because of a correlation between the constituent elements of the Function Point estimation method; therefore, the individual Function Point elements are not independent. These remarks involve criticism of the design theory and some authors claim that the method should be improved. In general, the internal consistency of a design theory can be defined as consistency between the theory's elements, both among elements of the same type and between different types of element.

\section{Internal Consistency for Design Theory Elements of the Same Type}

An example of internal consistency for design theory elements of the same type is the consistency of the system of design theory purposes and scopes. For a system of purposes and scopes, a researcher must prove that the purposes do not formally contradict each other. ${ }^{6}$

\section{The Importance of Internal Consistency among the Constructs Used}

The requirements for internal consistency of constructs differ from those for other design theory elements. Constructs "form the vocabulary of a domain" (March and Smith 1995). A necessary condition for internal consistency of constructs is a clear and concise definition of each construct and each relationship between them. A consistent use of the same terminology is essential when describing any theory. If terms are only vaguely defined, it is impossible to determine if they are used consistently.

Homonyms, including subtle homonyms, and synonyms should be avoided. Synonyms are different words with identical meaning. A homonym is one of a group of words that share the same spelling and the same pronunciation, but have different meanings. A subtle homonym is a word with slight differences or nuances in meaning. Subtle homonyms are sometimes difficult to detect in an argumentation. Used wittingly or unwittingly, they can lead to an invalid argumentation.

6 Formally, a contradiction is defined as a statement of the form " $a$ and not $a$." Whilst such a formal contradiction is invalid, the formulation of concurrent goals is allowed, of course. Two concurrent goals might be costs and quality. 


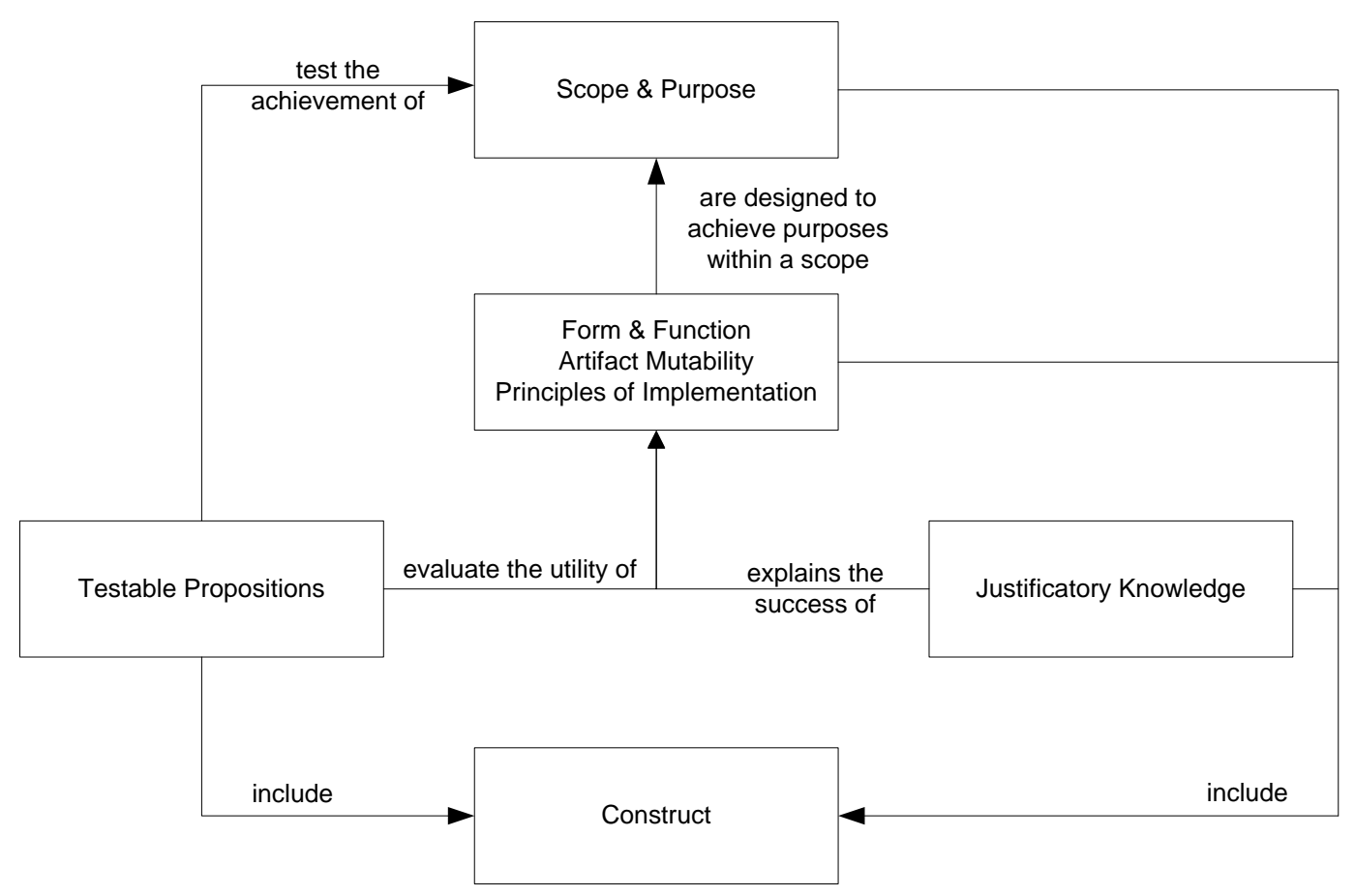

Figure 3. Mutual dependencies between components of a design theory as defined by Gregor and Jones (2007)

\section{Internal Consistency for Design Theory Elements of Different Types}

Design theory elements of different types should be consistent one with another. Generally, all elements should be consistent with all others. Nonetheless, some design theory elements depend more directly on others. These relationships of mutual dependencies are depicted in Figure 3.

The purpose and scope of a design theory should be consistent with any other element of the design theory as they define "what the system is for" (Gregor and Jones 2007). Purpose and scope are the leading properties of a design theory. All other elements of a design theory should be aligned with purpose and scope, especially form and function, artifact mutability, principle of implementation, and testable propositions.

Form and function, artifact mutability, and principles of implementation are designed to achieve one or more purposes within an applicable scope.

The testable propositions should evaluate the utility of form and function of the artifact, its principles of implementation, and the artifact mutability. They should test the achievement of one or more Purposes within an applicable scope.

Constructs "are representations of the entities of interest of a domain" (Gregor and Jones 2007). Constructs not only establish the relationship between theory and 
"world", but also build an important bridge between all elements of a design theory. They significantly contribute to an internally consistent structure of the artifact. Scope and purpose, testable propositions, form and function, artifact mutability, principles of implementation, and justificatory knowledge all include constructs. As stated above, the terminology should be internally consistent.

Justificatory knowledge or kernel theories play a special role in design research. Justificatory knowledge is not designed; it is given and must therefore be discovered (Purao 2002). As a consequence, justificatory knowledge is not orientated toward the scope and purpose of an artifact, but is autonomous. In IS, it is mainly behavioral research that is aimed at discovering such knowledge (Hevner et al. 2004, March and Smith 1995).

\section{External Consistency (K2b)}

Kuhn (1977) states that traditional theories should be externally consistent. By this, he means that theories should be in accordance with the common knowledge within the discipline. At the same time, Kuhn also immediately admits that revolutionary theories are often innovative because they do contradict common knowledge. He again takes the rejection of the geocentric world view by Copernicus as an example.

IS design theories should also be consistent with the IS knowledge base. Hevner et al. (2004) describe how the IS knowledge base can be fruitfully used for developing new design theories. Goldkuhl (2004) describes how design theories can be grounded on traditional theories in the field.

In the previous sub-section, we stated that consistency with justificatory knowledge is an aspect of internal consistency. Justificatory knowledge should be used for justifying form and function of the artifact, its mutability, and its principles of implementation. It establishes the link between the artifact and the knowledge base (Hevner et al. 2004). In contrast with internal consistency, external consistency is not limited to the justificatory knowledge (respectively to the kernel theories) explicated in the design theory, but refers to all relevant knowledge. Whilst internal consistency aims for consistency with a selected part of the knowledge base, external consistency refers to the selection of an appropriate part of the knowledge base. A broad review of the knowledge base is necessary for proving the external consistency of the artifact constructed (Hevner et al. 
2004, Peffers et al. 2006, Peffers et al. 2007). By way of illustration, we list some relevant questions for external consistency (admitting that this list is certainly not complete): (1) Have all relevant parts of the knowledge base been reviewed before formulating the design theory? (2) Is the choice of justificatory knowledge justified? (3) How does the design theory deal with contradictory knowledge, i.e. knowledge that does not support design decisions taken?

Furthermore, external consistency also refers to the choice of constructs. In many cases, it will be desirable for the constructs of the artifact to be consistent with constructs generally used. Such consistency simplifies the comparison of one design theory with others.

A first limitation of external consistency is mentioned by Kuhn (1977) himself: According to traditional theories, IS design theories are often revolutionarily progressive because they do contradict common knowledge. When Codd (1970) developed the relational model for databases, his ideas were fundamentally different from techniques for storing, manipulating, and deleting data used at the time. Nevertheless, his approach was highly innovative.

A second limitation of the external consistency of IS design theories is the inconsistency of the knowledge base. The IS knowledge base is more contradictory in itself than, for instance, that of physics. As an example, the market-based view contradicts the resource-based view. If a design theory is based on one of these two theories, it must consequently contradict the other. A design researcher should therefore always state explicitly where consistency with the knowledge base is intended and where it is not. The justificatory knowledge respectively the kernel theories as a component of a design theory can be used for this explication.

\section{Scope (K3)}

Kuhn (1977) states that the broader the scope of a theory, the better that theory will be: "a theory's consequences should extend far beyond the particular observations, laws, or subtheories it was initially designed to explain".

For design theories, scope and purpose should be broad, too. For instance, Hevner et al. (2004) claim design research artifacts to be general. The broader the scope and purpose of a design theory, the better that design theory will be.

A broad purpose and scope are useful for practical reasons. A knowledge base with a manageable number of design theories is desirable. The broader the pur- 
pose and scope of a design theory, the smaller the number of elements of the body of knowledge that are necessary to cover the object of IS. Artifacts with a broad purpose and scope are, among other things, helpful for communicating them to practitioners and for teaching.

The scope and purpose of a design theory can be enlarged by adapting the artifact to different purposes and scopes without its usefulness decreasing. With this in mind, Gregor and Jones (2007) mention artifact mutability as a component of a design theory. For the method artifact, Bucher et al. (2007) propose a concept for the situational adaptability of methods to different contexts and purposes. ${ }^{7}$

A technical problem occurs when comparing two design theories with this criterion. In the introduction to this section, we stated: If two design theories only partially have the same purpose and scope, then only those two parts of the artifact which cover identical purpose and scope will be comparable. This rule is, of course, not applicable for the criterion in question. Instead, the rule should be modified for this criterion as follows: If one design theory $A$ covers a purpose and scope that have previously been covered by more than one design theory $B_{1} \ldots B_{n}$, $n \geq 2, A$ is ceteris paribus progressive in comparison to $B_{1} \ldots B_{n}$.

\section{Simplicity (K4)}

Simplicity is often claimed as a quality factor of theories. William of Ockham said that entities must not be multiplied beyond necessity. ${ }^{8}$ Albert Einstein stated that everything should be made as simple as possible, but not simpler.

The Oxford English Dictionary (w/o author 1989) defines simple as "[n]ot complicated or involved; presenting little or no complexity or difficulty". Hence, simplicity is the opposite of complexity and difficulty. A simple design theory can be readily understood. Educated users of a design theory, in particular, often want to understand exactly what they are doing. The comprehensibility and simplicity of a design theory might therefore increase its acceptance by users.

Simplicity is also mentioned by March \& Smith (1995) and by Hevner et al. (2004) as a quality factor of artifacts. Above all, form and function, artifact muta-

7 Bucher et al. use a proprietary terminology and differentiate between context types and project types. However, this terminology can be mapped to our notion of scope (context type) and purpose (project type).

8 Charlesworth (1956) argues that the claim for simplicity commonly ascribed to William of Ockham ("Ockham's razor") has already been articulated by Aristotle. 
bility, and principles of implementation should be simple. Codd's relational model, for example, can be regarded as simple.

\section{Fruitfulness of new research findings (K5)}

\section{Fruitfulness of New Research Findings for Traditional Theories}

Kuhn (1977) names fruitfulness of new research findings as a criterion of a "good" traditional theory; and although he qualifies it as "a somewhat less standard item", he emphasizes its importance.

Kuhn again uses the example of the discovery of a heliocentric model for describing the movements of orbs. Copernicus was the first "modern" scientist who formulated a model based on a heliocentric world view. For two main reasons, however, this first heliocentric model by Copernicus was less accurate than the existing geocentric model which had dominated astronomy for 1,300 years: Firstly, the geocentric model has been incrementally improved over the years; and, secondly, Copernicus was mistaken in assuming circular movements of the planets around the sun instead of elliptical movements (as modeled by Ptolemy more than sixty years later). Kuhn (1977) states: “Copernicus's system, for example, was not more accurate than Ptolemy's until drastically revised by Kepler more than sixty years after Copernicus's death. If Kepler or someone else had not found other reasons to choose heliocentric astronomy, those improvements in accuracy would never have been made, and Copernicus's work might have been forgotten. More typically, of course, accuracy does permit discriminations, but not the sort that lead regularly to unequivocal choice" (Kuhn 1977). Kuhn therefore considers fruitfulness of new research findings to be a very important criterion.

Nevertheless, he is aware of the fact that the determination of the fruitfulness of a theory is difficult, especially if the theory is "new". Today, we know that Kepler's theory opened up an immense space for further research. Kepler himself and the wise ones among his contemporaries might have sensed that the heliocentric world view is important for further research; nevertheless, none of them could have known its real importance and the further progress it made possible. 


\section{Fruitfulness of New Research Findings for Design Theories}

Fruitfulness of new research findings is also an important criterion for IS design theories. For Hevner et al. (2004), IS artifacts (and behavioral theories) belong to the IS knowledge base and form the basis for further research. Markus et al. (2002) state that their "conceptualization is only as good as its implications for future research".

We therefore strongly support the arguments given by Kuhn as well as by Markus et al. (2002) for the fruitfulness of new research findings. For instance, Codd's (1970) proposition for a relational model for databases had a major influence on database development and continues to be the theoretical foundation for state-ofthe-art databases.

The Problem of an Evaluation of the Fruitfulness of New Research Findings

Nevertheless, there is a practical problem associated with this criterion: As in the case of traditional theories, it is often difficult to determine the fruitfulness of a design theory when it is constructed.

To illustrate this problem, we refer to the definition of a design theory by Venable (2006a, 2006b). Above, we show Figure 1 by Venable (2006a, 2006b) which shows that a design theory links some solution technology concept to the aspect of the problem that it addresses. In Figure 4, we pick up on this idea and show the utility (on the ordinate axis) of different solutions (on the axis of abscissae) with respect to one problem ${ }^{9}$. The utility of each solution is shown by different curves. Of course, a priori, we do not know the shape of the curves - and we may well never do so.

The graphic is based on the metaphysical assumption that good solutions are often close to each other (these are the solutions on one curve), but that there are often good different solutions which are quite far away (illustrated by different curves in Figure 4). For instance, artifact $A_{l}$ is a first solution to a problem. This solution can be improved incrementally by optimizing it, e.g. to solution $A_{2}$ and successively to solution $A_{3}$. This is what Kuhn (1970, p. 35-42) describes as normal sci-

\footnotetext{
${ }^{9}$ Venable's (2006a, 2006b) definition of a problem is strongly related to Gregor and Jones' (2007) definition purpose and scope for a design theory because the purpose of a design theory often is to address a specific problem with a given scope.
} 
ence and what he calls "puzzle solving". As described above, Kuhn assumes that a phase of normal science is followed by a phase of revolutionary science in which common fundaments of a discipline are questioned and new assumptions are made. Solution $B$ and solution $C$ are revolutionarily new IS design theories. The utility of both solutions is smaller than that of $A_{3}$ and even than that of $A_{2}$; but both have the potential to be optimized. However, the potential of solution $B$ is very low while that of solution $C$ is very high. Solution $C$ is therefore very fruitful of further research whilst $B$ is not at all - it can never lead to solutions that are better than the existing solution $A_{3}$.

The problem related to the fruitfulness of new research findings is that the fulfillment of this criterion can only be determined in the long run. After having constructed an artifact that fundamentally differs from common solutions, one cannot be sure whether it has a large potential (like artifact $C$ ) or a small one (like artifact $B)$. However, since revolutionary solutions at least often have the potential to be fruitful of further research we adopt this criterion for design theories even though the researcher will not be able to evaluate the actual potential of his or her design theory.

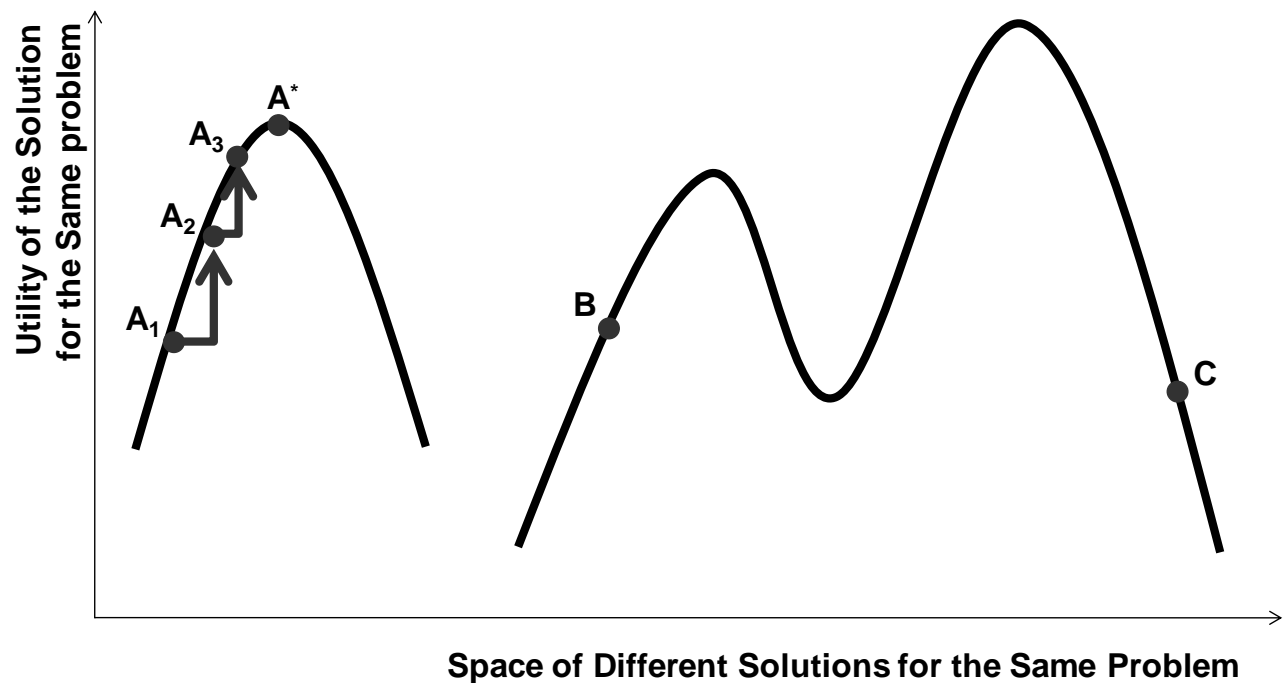

Figure 4: Utility and potential of a solution

\section{Summary of the Criteria}

Kuhn names five criteria for "good" traditional theories. We adapted these criteria to design theories: While a traditional theory should be accurate, i.e. it should have a high explanatory and/or predictive power, a design theory should be useful. Three kinds of utility can be differentiated: gross utility, net utility, and efficiency. 
A design theory, just like a traditional theory, should be internally and externally consistent. As the purpose and scope of a design theory belong together, a design theory should not only have a broad scope as traditional theories ought to, but also cover a variety of purposes. Like traditional theories, a design theory should be simple. Finally, a traditional theory should be fruitful of further research. With respect to IS design theories, we perfectly agree with Kuhn. Nevertheless, for epistemological reasons, the extent to which a design theory is fruitful of further research cannot be determined. The six criteria are summarized in Table 7. 
Table 7: Summary of the five evaluation criteria for design theories

\begin{tabular}{|c|c|c|}
\hline $\begin{array}{l}\text { Traditional } \\
\text { Theories }^{10}\end{array}$ & $\begin{array}{l}\text { Design } \\
\text { Theories }\end{array}$ & Specification \\
\hline \multirow{3}{*}{$\begin{array}{l}\text { Accuracy } \\
\text { (explanato- } \\
\text { ry/ predic- } \\
\text { tive power) }\end{array}$} & \multirow[t]{3}{*}{ Utility } & $\begin{array}{l}\text { The utility of a design theory is the artifact's ability to fulfill its pur- } \\
\text { pose if the purpose itself is useful. The purpose of an artifact is only } \\
\text { useful if it is relevant for business. }\end{array}$ \\
\hline & & $\begin{array}{l}\text { The purpose of an artifact is concretized by testable propositions. } \\
\text { They help to prove that the artifact fulfills its purpose. }\end{array}$ \\
\hline & & $\begin{array}{l}\text { Three forms of utility can be differentiated: gross utility (absolute } \\
\text { output), net utility (difference between output and input), and effi- } \\
\text { ciency (output divided by input). }\end{array}$ \\
\hline \multirow{5}{*}{$\begin{array}{l}\text { Internal } \\
\text { consistency }\end{array}$} & \multirow{5}{*}{$\begin{array}{l}\text { Internal con- } \\
\text { sistency }\end{array}$} & Each element of a design theory should be consistent with itself. \\
\hline & & $\begin{array}{l}\text { A consistent system of constructs is the common basis for all design } \\
\text { theory elements. All constructs used should be defined concisely. In } \\
\text { the interests of consistent terminology, it is important that homonyms, } \\
\text { including subtle homonyms, and synonyms are avoided. }\end{array}$ \\
\hline & & $\begin{array}{l}\text { Form and function of the artifact, artifact mutability, principles of } \\
\text { artifact implementation, and testable propositions directly depend on } \\
\text { scope and purpose. }\end{array}$ \\
\hline & & $\begin{array}{l}\text { Testable propositions refer to form and function of the artifact, arti- } \\
\text { fact mutability, and its principles of implementation. }\end{array}$ \\
\hline & & $\begin{array}{l}\text { Justificatory knowledge should justify form and function of the arti- } \\
\text { fact, artifact mutability, and its principles of implementation. }\end{array}$ \\
\hline \multirow[t]{3}{*}{$\begin{array}{l}\text { External } \\
\text { consistency }\end{array}$} & \multirow[t]{3}{*}{$\begin{array}{l}\text { External } \\
\text { consistency }\end{array}$} & $\begin{array}{l}\text { Justificatory knowledge should be consistent with the knowledge } \\
\text { base. Consistency with a selected part of the knowledge base, i.e. } \\
\text { with justificatory knowledge (or with kernel theories), is covered by } \\
\text { internal consistency. In addition, external consistency refers to a } \\
\text { sound justification of the choice of justificatory knowledge (or of } \\
\text { kernel theories); moreover, the relationship to parts of the knowledge } \\
\text { base that contradict design decisions should be explicated. }\end{array}$ \\
\hline & & Constructs should be consistent with constructs commonly used. \\
\hline & & $\begin{array}{l}\text { Sometimes, design theories are innovative simply because they con- } \\
\text { tradict commonly accepted assumptions. }\end{array}$ \\
\hline \multirow{2}{*}{$\begin{array}{l}\text { Broad } \\
\text { scope }\end{array}$} & \multirow{2}{*}{$\begin{array}{l}\text { Broad } \\
\text { purpose and } \\
\text { scope }\end{array}$} & Scope and purpose of an artifact should be broad. \\
\hline & & $\begin{array}{l}\text { If one design theory } A \text { covers a purpose and scope that has previously } \\
\text { been covered by more than one design theory } B_{1} \ldots B_{n}, n \geq 2, A \text { is } \\
\text { ceteris paribus progressive in comparison to } B_{1} \ldots B_{n} \text {. }\end{array}$ \\
\hline \multirow[t]{2}{*}{ Simplicity } & \multirow[t]{2}{*}{ Simplicity } & $\begin{array}{l}\text { Design theories should be simple in order to be easily understandable } \\
\text { und manageable. }\end{array}$ \\
\hline & & $\begin{array}{l}\text { Simple artifacts will often cost less when used. This aspect is already } \\
\text { covered by two notions of utility: net utility and efficiency. }\end{array}$ \\
\hline \multirow{2}{*}{$\begin{array}{l}\text { Fruitfulness } \\
\text { of new } \\
\text { research } \\
\text { findings }\end{array}$} & \multirow{2}{*}{$\begin{array}{l}\text { Fruitfulness } \\
\text { of new } \\
\text { research } \\
\text { findings }\end{array}$} & $\begin{array}{l}\text { Design theories should disclose new phenomena or previously unnot- } \\
\text { ed relationships among already known phenomena. }\end{array}$ \\
\hline & & They should initiate/stimulate further research activities. \\
\hline
\end{tabular}

10 Criteria of progress for traditional theories according to Kuhn (1977). 


\section{Conflicting Criteria}

We still have to make one important remark regarding the criteria. For any two concurring design theories, the criteria will often conflict. For instance, one of two design theories applicable to the same purpose and scope might be better justified ("external consistency") whilst the other is simpler ("simplicity"). In this paper, we do not want to rank the criteria. Needless to say, there is broad consensus in the literature that the utility of a design theory (or of a design science research artifact) is a very important criterion (e.g., Gregor 2006, Gregor and Jones 2007, Hevner et al. 2004, Kuechler and Vaishnavi 2008, March and Smith 1995, Markus et al. 2002, Venable 2006b, Walls et al. 1992). Apart from the importance of utility, however, it is difficult to rank the criteria and to justify any ranking because it soon involves answering further normative questions like: "How big or important is the problem to be solved?" Instead, we would like to follow the approach proposed by Kuhn (1977) and introduce the ceteris paribus clause as Kuhn did. In accordance with his definition of this clause for traditional theories, a design theory $A$ is progressive in comparison with a design theory $B$ if $A$ fulfills at least one criterion in a better way than $B$ and if the fulfillment of all other criteria belonging to the set remains equal. To describe the fact that one criterion is changed while all other criteria remain equal, the Latin concept "ceteris paribus" (English: "all other things remain equal") is used. Such rules for progress using the ceteris paribus clause are also called rules for partial progress.

\section{Discussion}

We propose criteria of progress for design theories in order to stimulate the discussion on progress in IS DSR. In this paper, we want to briefly discuss two important aspects of the criteria. In the first sub-section, we look at the problem of measurement, and in the second sub-section, we compare our criteria with those mentioned by March and Smith (1995).

\section{Epistemological and Methodological Approaches}

In this paper, we aim to define criteria of progressivity for design theories and do not focus on how to determine the extent to which a criterion is fulfilled. Nevertheless, we briefly discuss the issue of determining the fulfillment of a criterion. It is entirely beyond the scope of this paper to define methodologies for measuring 
the cost or utility of design theories. We therefore restrict ourselves to showing different approaches to the problem. Nevertheless, in the second sub-section we very briefly discuss the application of the different methodologies taking the example of utility. Finally, we briefly draw a conclusion.

\section{Epistemological and Methodological Variety in Information Systems De- sign Science Research}

The definition of criteria of progress is an ontological task; the construction of a methodology for determining progress according to these criteria is a methodological task. A methodology is based not only on ontological but also on epistemological assumptions; epistemology can therefore be considered as an "intermediator" between ontology and methodology. Epistemology is the science of knowledge; amongst others, it is concerned with opportunities for and restrictions to achieving knowledge. In information systems research, a variety of epistemological approaches is discussed; epistemological pluralism is a fact of IS DSR research which has even been regarded as an advantage of our discipline by some authors (Frank 2006, Niehaves 2007a, Niehaves 2007b).

In the discourse of epistemology, epistemological frameworks for IS research have been proposed (Becker and Niehaves 2007, Fitzgerald and Howcroft 1998, Frank 2006, Figure 2). Exemplarily, the framework by Becker and Niehaves (2007), which is based on different epistemological frameworks, is presented in Table 8. We can see that Becker and Niehaves define three layers between the ontological aspect (I) and the methodological aspect (V).

Table 8: Epistemological framework (Becker and Niehaves 2007)

\begin{tabular}{|c|c|}
\hline Question & Possible answers \\
\hline $\begin{array}{l}\text { I. What is the object of cognition? } \\
\text { (Ontological aspect) }\end{array}$ & $\begin{array}{l}\text { Ontological realism, Ontological idealism, } \\
\text { Kantianism }\end{array}$ \\
\hline $\begin{array}{l}\text { II. What is the relationship between cognition } \\
\text { and the object of cognition? }\end{array}$ & Epistemological realism, Constructivism \\
\hline $\begin{array}{l}\text { III. What is true cognition? } \\
\text { (Concept of truth) }\end{array}$ & $\begin{array}{l}\text { Correspondence theory of truth, Consensus } \\
\text { theory of truth }\end{array}$ \\
\hline IV. Where does cognition originate? & Empiricism, Rationalism, Kantianism \\
\hline $\begin{array}{l}\text { V. By what means can cognition be achieved? } \\
\text { (Methodological aspect) }\end{array}$ & Inductivism, Deductivism, Hermeneutics \\
\hline
\end{tabular}

In the following, we focus on one central epistemological concept which might help us to close the gap between the definition of criteria of progress and a meth- 
od for measuring these criteria: the concept of truth (question III according to Becker and Niehaves, cf. Table 8). Whilst Becker and Niehaves (2007) identify two concepts of truth, Frank (2006, Figure 2) identifies three concepts of truth and relates them to different methodologies. We slightly extend Frank's framework and show it in Table 9.

Table 9: Relationship between concepts of truth and empirical methodologies (acc. to Frank 2006, Figure 2, slightly extended)

\begin{tabular}{ll}
\hline Concept of truth & Methodology \\
\hline a. Correspondence theory of truth & Laboratory experiment \\
& Field experiment \\
& Field Study \\
& Positivistic case study \\
b. Coherence theory of truth & Literature review \\
c. Consensus theory of truth & Discourse (with experts, e.g. in a focus group) \\
& Virtual discourse \\
\hline
\end{tabular}

Frank (2006) differentiates between the correspondence theory of truth, the coherence theory of truth, and the consensus theory of truth. ${ }^{11}$ A correspondence theory of truth "is the view that truth is correspondence to a fact" (David 2009). For instance, "snow is white" is true if and only if snow is white. Experiments, field studies, and positivistic case studies are research methods that rely on this paradigm. In contrast, a "coherence theory of truth states that the truth of any (true) proposition consists in its coherence with some specified set of propositions" (Young 2008). A research method for stating the coherence of a proposition with a set of propositions is a literature analysis (Frank 2006, figure 2). Finally, Habermas' consensus theory of truth, also called discourse theory of truth, states that a proposition is true if a consensus is achieved on this statement in a justified, non-hierarchical discourse (cf. e.g. Habermas 1984). A research method relating to this paradigm is a discourse with one expert or a group of experts (focus groups, cf. Gibson and Arnott 2007). Such a discourse can also be led virtually (Frank 2006).

11 We cannot discuss the different theories of truth in detail here. David (2009) gives a short overview of the variety of theories discussed under the label of a correspondence theory of truth and discusses some of its major advantages and disadvantages. Young (2008) deals with the correspondence theory of truth. For the consensus theory of truth, we directly refer to its most popular proponent: Jürgen Habermas (cf. e.g. Habermas 1984). 
We present the framework in Table 9 in order to show that a variety of approaches exist for determining the extent to which a criterion of progress is fulfilled by a design theory. Of course, all the methods listed in Table 9 have specific advantages and restrictions; nevertheless, a discussion of them is far beyond the scope of this paper. Moreover, we do not guarantee the completeness of the framework; this also exceeds the scope of this paper.

\section{Exemplary Discussion of Different Methodologies}

In this sub-section, we briefly discuss the applicability of the methodologies listed in Table 9 for evaluating the progressivity of design theories. To this end, we mainly refer to the criterion of utility. It should be clear that this discussion can be performed analogously with respect to other criteria.

Based on the correspondence theory of truth, experiments, field studies, and positivistic case studies are listed in Table 9.

In an experiment, a researcher generally observes dependent variables by influencing independent variables. An example of an experiment is given by Sobel and Clarkson (2002), ${ }^{12}$ they analyze the influence of a formal specification on the correctness, conciseness, and complexity of a computer. To this end, they compare computer programs of undergraduate students who have formally specified a solution with students who have not. Such experiments can be conducted to determine the utility of other design theories. Another example of an experiment is the test by Bodart et al. (2001) to establish whether optional elements should be used in conceptual modeling.

In case studies and field studies, phenomena are observed without influencing the system. Unlike case studies, field studies are characterized by an investigation of a high number of cases to enable statistical analyses. Field studies are frequently applied in IS behavioral research, but rarely in IS DSR.

In positivistic case studies, the utility of a prototype can be observed (cf. Frank 2006). For Gregor and Jones (2007), an "expository instantiation" is an additional part of a design theory, i.e. a "physical implementation of the artifact that can assist in representing the theory both as an expository device and for purposes of

12 The experiment is interesting from a methodological point of view because Sobel and Clarkson (2002) were heavily criticized by Berry and Tichy (2003) for methodological errors in the experiment design and its result. Sobel and Clarkson (2003) answer this criticism. 
testing". In case studies, the adoption of the expository instantiation of the design theory can be observed and its users can be asked for their experience.

It is certainly difficult to show that one design theory is more useful than another by performing a literature review for a design theory that has just been created. In such a situation, other methodologies seem to be more appropriate. Nevertheless, similarly to field studies, literature reviews can be helpful to compare the utility of two established design theories which are already largely discussed in literature. Especially when evaluating the extent to which a design theory is fruitful of further research, a literature review is an appropriate method.

Based on the consensus theory of truth, a discourse with and among experts is an easy way to estimate the utility of a design theory. Experts can judge whether they perceive the theory to be useful from their own experience. The role of focus groups in IS DSR is discussed for instance by Gibson and Arnott (2007).

Lastly, a discourse can also be conducted virtually in order to show the utility of a design theory (Frank 2006). Good arguments should be given for proving the utility of a design theory.

\section{Conclusion}

A variety of methodologies exists for evaluating the progressivity of design theories. These methodologies all have advantages and restrictions - as far as their applicability as well as their interpretability is concerned. It is not the case that every methodology is applicable for every situation. Nonetheless, we have good reasons to assume that at least one appropriate methodology can be found for each of the criteria. Although the consensus theory of truth might be a relatively weak concept of truth, it should be applicable in nearly all situations. A further discussion of epistemological and methodological aspects is beyond the scope of this paper.

\section{Comparison of March and Smith's (1995) Evaluation Criteria with the Criteria of Progress Proposed}

\section{Comparison of the Criteria}

In the section on related work, we have presented a set of evaluation criteria for IS DSR artifacts of different types proposed by March and Smith (1995), cf. Table 5. 
This set of criteria was the most comprehensive set we could find. In the section on terminological and conceptual foundations, we have already discussed the relationship between IS design theories, IS design science research, and IS DSR artifacts. We would like to refer again to Gregor and Jones (2007, p. 320) who state “that 'constructs, models and methods' are all one type of thing and can be equated to theory or components of theory, while instantiations are a different type of thing altogether."

As IS DSR artifacts and IS design theories are related, we would like to compare our criteria to those defined by March and Smith (1995). The comparison aims to evaluate in how far our proposition corresponds to other proposition: We mainly ask the following two questions:

(1) Is our proposition of criteria broad enough, i.e. complete? Have we ignored any relevant or important criteria?

(2) Is our proposition of criteria well focused? Have we proposed any irrelevant or unimportant criteria?

Table 10: Schematic comparison of the evaluation criteria for IS DSR artifacts by March and Smith (1995) with the proposed criteria of progress for design theories

\begin{tabular}{|c|c|c|c|c|c|c|}
\hline & 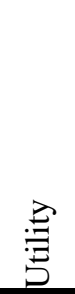 & 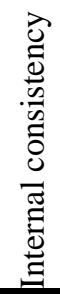 & 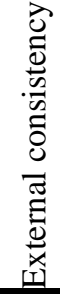 & 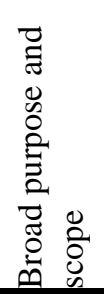 & 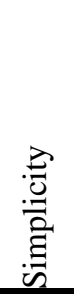 & 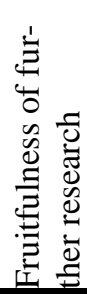 \\
\hline Completeness & & $\mathrm{X}$ & & & & \\
\hline Ease of use & $\mathrm{X}$ & & & & $\mathrm{X}$ & \\
\hline Effectiveness & $\mathrm{X}$ & & & & & \\
\hline Efficiency & $\mathrm{X}$ & & & & & \\
\hline Elegance & & & & & $\mathrm{X}$ & \\
\hline Fidelity with real world phenomena & & & $\mathrm{X}$ & & & \\
\hline Generality & & & & $\mathrm{X}$ & & \\
\hline Impact on the environment and on the artifacts' users & $\mathrm{X}$ & & & & & \\
\hline Internal consistency & & $\mathrm{X}$ & & & & \\
\hline Level of detail & & $\mathrm{X}$ & & & & \\
\hline Operationality & $\mathrm{X}$ & & & & & \\
\hline Robustness & & & & $\mathrm{X}$ & & \\
\hline Simplicity & & & & & $\mathrm{X}$ & \\
\hline Understandability & & & & & $\mathrm{X}$ & \\
\hline
\end{tabular}

In the lines of Table 10, we list March and Smith's (1995) evaluation criteria for IS DSR artifacts; we ignore the fact that the criteria refer to artifacts of a specific 
type. In the rows of Table 10, we list the six criteria of progress as proposed in this paper. As Table 10 shows, each of March and Smith's (1995) criteria can be mapped to at least one of the criteria we propose. In Table 11, we explain the relationship between the criteria.

Table 11: Explanation of the relationship between March and Smith's (1995) criteria and our proposition

\begin{tabular}{|c|c|}
\hline Criterion & Utility \\
\hline Completeness & $\begin{array}{l}\text { Completeness is one notion of internal consistency. If a design theory is } \\
\text { incompletely described, it cannot be internally consistent. }\end{array}$ \\
\hline Ease of use & $\begin{array}{l}\text { Ease of use is strongly related to utility. Only a design theory resulting in } \\
\text { an easily usable artifact is useful. }\end{array}$ \\
\hline Effectiveness & Effectiveness is an aspect of utility. \\
\hline Efficiency & Efficiency is an aspect of utility. \\
\hline Elegance & $\begin{array}{l}\text { Elegance is related to simplicity. In fact, simplicity is a special aspect of } \\
\text { elegance. }\end{array}$ \\
\hline $\begin{array}{l}\text { Fidelity with real } \\
\text { world phenomena }\end{array}$ & $\begin{array}{l}\text { The fidelity with real world phenomena corresponds to external con- } \\
\text { sistency. }\end{array}$ \\
\hline Generality & Generality is the same as a broad purpose and scope. \\
\hline $\begin{array}{l}\text { Impact on the envi- } \\
\text { ronment and on the } \\
\text { artifacts' users }\end{array}$ & $\begin{array}{l}\text { The impact on the environment and on the artifact's users is a side effect. } \\
\text { In this paper, we discuss side effects in the section about utility. Side } \\
\text { effects can increase or decrease utility. }\end{array}$ \\
\hline Internal consistency & $\begin{array}{l}\text { As March and Smith (1995) did, we propose internal consistency as a } \\
\text { criterion. }\end{array}$ \\
\hline Level of detail & $\begin{array}{l}\text { An appropriate level of detail is incorporated by internal consistency if it } \\
\text { refers to the relationship between the purpose and scope of a design theory } \\
\text { and its other components. If the level of detail refers to the size of the } \\
\text { problem addressed, it corresponds to our criterion broad purpose and } \\
\text { scope. }\end{array}$ \\
\hline Operationality & Operationality is an aspect of utility. \\
\hline Robustness & $\begin{array}{l}\text { The robustness of an algorithm refers to its applicability over the whole } \\
\text { spectrum of purpose and scope. It is therefore a notion of a broad purpose } \\
\text { and scope. }\end{array}$ \\
\hline Simplicity & As March and Smith (1995) did, we proposed a criterion called simplicity. \\
\hline Understandability & Understandability is strongly related to simplicity. \\
\hline
\end{tabular}

\section{Discussion of the Comparison Result}

Firstly, we analyze whether our criteria are broad enough. Table 10 shows that each of March and Smith's (1995) criteria is related to at least one of the criteria we propose. In most cases, our criteria are more general than March and Smith's (1995) ones. An exception is the "elegance". In our set of criteria, only one notion of criteria is included: simplicity.

Secondly, we discuss if our criteria are well focused, i.e. whether we propose any irrelevant or unimportant criterion. Most of March and Smith's (1995) criteria are 
more concrete. This is certainly due to the fact that the criteria are defined for a specific artifact type. Our criterion "fruitfulness of further research", has no equivalent in any of March and Smith's (1995) criteria. Nevertheless, March and Smith (1995) clearly emphasize the importance of the novelty or innovativeness of an artifact. As we showed in this paper, the innovativeness of an artifact is strongly related to its fruitfulness of further research findings. It is unclear why March and Smith (1995) do not include this criterion to their set of evaluation criteria. We think that the fruitfulness of a design theory for further research is an important criterion and that it should be part of our analysis.

\section{Application of the Criteria of Progress to Codd's Model for Relational Databases}

In this section we will give an example of the application of our criteria of progress to a design theory in order (1) to convey more clearly what the criteria mean, (2) to show how they provide value (their utility), and (3) to illustrate how they can be applied.

However, this demonstration has to remain superficial in two aspects: (a) we will not be able to illustrate the design theories adequately due to restrictions of length and (b) we will not be able to define precise measures for each criterion. Limitation (a) applies to this contribution only. It is less of a problem for articles evaluating their contribution by employing the criteria presented here. Limitation (b), however, is an immaturity at method level which we have discussed in the previous section.

For the purposes of this paper, we cannot determine the fulfillment of the criteria based on the correspondence theory of truth. It would be too laborious to conduct an experiment, a field study, or a case study. Our argumentation is mainly based on a discourse of different arguments, i.e. on the consensus theory of truth. Where possible, we cite literature; in this case, our argumentation is also based upon the coherence theory of truth.

\section{Codd's Design Theory for Relational Databases}

To demonstrate application of the criteria we have chosen a very classic example - Codd's relational database theory (Codd 1970). We have chosen Codd's work in the tradition of Walls et al. (1992) and Gregor and Jones (2007) who also refer- 
ence Codd since, as Walls et al. (1992, p. 43) put it, it "is probably the most completely developed example of a design theory in the information systems discipline".

Codd developed the relational database model as an alternative concept to prerelational approaches, namely tree-structured files and network models of data. Therefore, the application of our criteria of progress is aimed at evaluating the progress of design theories behind Codd's relational model over the design theories behind pre-relational tree and network models of data.

Codd's main design concern was to improve human productivity related to information systems. In particular, Codd set out to decouple the way data is organized in the machine (the internal representation) and the way users query or update data through application programs (the external representation). To this end, Codd contributed the relational model for data representation as well as a procedure model for the normalization of tables. The resulting design method is based on set theory and relational algebra.

\section{Utility}

Codd developed the relational model based on his practical experience with the use of pre-relational database systems while working for IBM. He concluded that for IT departments to meet the growing demands of end users two strategies were necessary: (i) enable end users to work directly with data stored in computers, and (ii) increase the productivity of application developers in making data available through application programs (Codd 1982). For both of these goals relational database systems provide a foundation based on the design principles of data independence, structural simplicity, and relational processing. In 1982, Codd concludes that, bound to a specific purpose and scope (improve productivity of end users and application programmers working with data), the utility of his approach has been proven by test and production installations of relational databases. Since the publication of Codd's initial article in 1970 there have also been a number of articles accessing the utility of the relational model from various perspectives of utility and therefore purpose and scope (e.g. Michaels et al. 1976). From today's perspective, the utility of Codd's relational approach is demonstrated by its predominance in the field and the consensus among the database community concerning this status. 
Again, it is important to mention that utility is always related to a specific purpose and scope. Database systems based on relation and pre-relational models fulfill the purpose of managing large amounts of data equally well for the multiple users. However, when it comes to frequent changes in the internal or external representation of data, relational databases clearly provide higher net utility since changes to either representation remain local to that representation. For pre-relational approaches, changes in one representation had to be propagated to the other representation as well. On the other hand, in the early days of relational systems the lack of performance was often mentioned as a downside of relational databases compared with pre-relational systems. Therefore, if performance was an issue, pre-relational databases had a higher gross and net utility.

\section{Internal Consistency}

A coherent system of constructs is the common basis for all design theory elements. To completely test internal consistency of the relational and the prerelational models we would have needed to analyze all elements of the respective design theories - which is impossible in this contribution. Here, we will use the examples from Codd's relational model given by Gregor and Jones (2007) (Table 12) and contrast these with examples from the pre-relational approaches.

Table 12: Examples of Codd's design theory elements based on Gregor and Jones (2007)

\begin{tabular}{|c|c|}
\hline Design theory elements & Relational model (Codd 1970, Codd 1982) \\
\hline $\begin{array}{l}\text { Purpose and scope of the } \\
\text { theory }\end{array}$ & $\begin{array}{l}\text { Better database technology is needed to increase human produc- } \\
\text { tivity because pre-relational approaches are failing in this respect. }\end{array}$ \\
\hline $\begin{array}{l}\text { Principles of form and } \\
\text { function incorporating } \\
\text { underlying constructs. }\end{array}$ & $\begin{array}{l}\text { The relational database model has principles such as "the order of } \\
\text { rows in the tables is arbitrary and irrelevant." }\end{array}$ \\
\hline Artifact mutability & $\begin{array}{l}\text { The argument is made that the relational model allows for rela- } \\
\text { tively simple adaptation and change to base tables, while user } \\
\text { views appear unchanged. }\end{array}$ \\
\hline Testable propositions & $\begin{array}{l}\text { Statements are made such as "Activities of users at terminals and } \\
\text { most application programs should remain unaffected when the } \\
\text { internal representation of data is changed". }\end{array}$ \\
\hline $\begin{array}{l}\text { Justificatory knowledge } \\
\text { (kernel theory) }\end{array}$ & $\begin{array}{l}\text { It is shown how the relational model works by reference to under- } \\
\text { lying set theory and also human cognitive processes. }\end{array}$ \\
\hline $\begin{array}{l}\text { Principles of implemen- } \\
\text { tation }\end{array}$ & $\begin{array}{l}\text { Guidelines are given on how to produce a relational database } \\
\text { through normalization procedures. }\end{array}$ \\
\hline
\end{tabular}

Form and function of the artifact, artifact mutability, principles of artifact implementation, and testable propositions directly depend on scope and purpose. Testable propositions refer to form and function of the artifact, artifact mutability, and 
its principles of implementation. Justificatory knowledge should justify form and function of the artifact, artifact mutability, and its principles of implementation. In the case of the section of Codd's relational model dealt with here, the criterion of internal consistency seems to be fulfilled. However, the question is whether internal consistency is better with the relational than with the pre-relational model. Here again, the dependency on purpose and scope becomes obvious. If the purpose is high user productivity and the scope includes frequently changing external and internal representations, several other elements of pre-relational systems, especially the principles of form and function, are inconsistent with purpose and scope.

\section{External Consistency}

Codd's relational theory is based on set theory, respects findings on human cognitive processes, and uses relational algebra. Although Codd significantly contributed to relational algebra, his model is based on commonly accepted constructs and theories and should therefore be considered externally consistent.

On the other hand, the relational model significantly differs from tree or network models previously used to store, read, and manipulate large amounts of data. This difference, however, may be attributed to the innovativeness of Codd's approach rather than to external inconsistency. Again, referring to specific purpose and scope, Codd's approach has a higher external consistency compared with prerelational approaches, especially when human cognitive processes are concerned.

\section{Broad Purpose and Scope}

The relational model has very broad purpose and scope. Increasing a database developer's/user's productivity is in itself a very broad purpose. But other purposes are also fulfilled, e.g. equal performance in comparison with pre-relational models - even if this was not yet the case when Codd defined the relational model. Codd himself always advocated the performance aspect of the relational model (Codd 1982). It is hard to prove which approach has broader purpose and scope since no finite list of purposes and scopes exists for either of them. For the majority of users, however, purpose and scope of the relational model are at least as broad as purpose and scope of pre-relational models. From today's perspective, 
only the object-oriented paradigm restricts the scope of beneficial and efficient application of the relational model.

\section{Simplicity}

Design theories should be simple in order to be easily understandable und manageable. With Codd's relational model two views on simplicity can be differentiated: (i) the simplicity of the relational model itself as well as the simplicity of the design method for the normalization of tables, and (ii) the use of the resulting relational database. While, with the current level of detail, we cannot tell whether the relational approach is simpler than the pre-relational approaches, the use of the resulting relational database is simpler by design. Codd's goal was that using relational models should be easy so that all kinds of users or programmers could use the data and communicate about its use. This major design principle is referred to by Codd as the "communicability objective".

\section{Fruitfulness of New Research Findings}

Codd's relational model is a classic example of a design theory that opened up an entire solution space. In this solution space a broad variety of research and application has been conducted. Examples of results range from Chen's Entity Relationship Model (Chen 1976) and practical applications of Data Warehousing and Business Intelligence (Devlin 1997, Inmon et al. 2008) to a broad range of commercial and open-source relational database management products.

However, while this evaluation and its result are obvious today, they were not obvious when Codd's initial paper was published. Even six years later, Michaels et al. state: "One point should be clear at this time: Since DBMSs are to be utilized by a wide spectrum of end users, no single approach to database management is desirable and no single approach is likely to emerge as dominant in the near future" (Michaels et al. 1976, p. 148). This statement illustrates the difficulties experienced when evaluating the future potential of a research result.

\section{Conclusion}

In demonstrating the application of our proposed criteria of progress we have further discussed what the criteria mean, and shown that they are suitable for identifying a progressive design theory. However, this demonstration also reveals the 
difficulties involved in actually applying these criteria in a rigorous manner. We have discussed this aspect in the previous section. The dependency of the evaluation result on purpose and scope is a fact. While this seems inevitable, it makes a reliable comparison of two design theories difficult.

\section{Conclusion}

\section{Summary}

Design research has become a respected and partially established paradigm in IS research. However, a number of theoretical questions are yet to be answered satisfactorily. One of these questions is: "What are criteria of progress for design theories?"

Although some authors define criteria for evaluating design theories, our literature review reveals that a coherent set of evaluation criteria has never been developed systematically. Our research is aimed at closing this gap.

We identified a set of six criteria for comparing two design theories: utility, internal consistency, external consistency, broad purpose and scope, simplicity, and, finally, fruitfulness of new research findings. The set of six criteria was systematically adopted from a set of criteria defined by Kuhn (1977) for "traditional" theories, i.e. theories for describing, explaining, and/or predicting phenomena in natural sciences. Epistemological and methodological issues of the criteria application are briefly discussed. An example served to illustrate the applicability of the set of criteria defined.

\section{Implications}

The criteria developed are relevant for advancements in design theory, on a theoretical level as well as for research practice.

On a theoretical level, our research confirms that utility is an important criterion for "good" design theories. Whereas the utility of a design theory might be the

only criterion of choice for a practitioner, from a scientific point of view, utility does not suffice. Criteria such as a broad purpose and scope, external consistency, or fruitfulness of new research findings usually do not directly correlate with utility; they are nevertheless important for fostering progress in the discipline. The criteria developed are helpful for illustrating the differences between the work of a 
practitioner (e.g. a consultant) whose only aim is to develop a useful solution for a one-off case and that of a design science researcher whose aim is also to contribute toward progress in his or her discipline.

On a practical level, our research findings help researchers to structure their evaluation of the progressivity of a design theory and even to construct progressive design theories. Although clear guidelines for measuring the criteria could not be given, this article helps IS design researchers to evaluate their artifact. The criteria are not only relevant for the evaluation phase, but also for the construction phase as the researcher can aim to construct design theories which exemplify our criteria.

\section{Limitations}

As stated in the introduction, our research is aimed at identifying criteria for evaluating design theories. We only briefly touched on the problem of measurement, i.e. epistemological and methodological aspects. Further research is necessary in this area.

Moreover, we could not prove that the set of criteria defined is complete. We argue that we derived criteria of progress from the philosophy of science and therefore propose a consistent set of criteria. Also our literature review of related work in IS did not bring up further or contradictory aspects. Nevertheless, we hope to stimulate and contribute toward a discussion on the criteria we proposed, which might lead to a broad consensus regarding a set of criteria.

Furthermore, in order to compare two design theories, both design theories must have (at least to some extent) the same purpose and scope. Although growing, the number of design theories is still small (cf. Walls et al. 2004). Therefore, it will be difficult - and often impossible - to find an explicated design theory that a newly developed design theory could be compared with. However, we argue that this problem is less severe than it seems to be at a first glance. It is true that only few design theories have been explicated; nevertheless, the way information systems are designed is often influenced by theoretical knowledge. When a new design theory is developed, we propose to reconstruct design theories that were used for solving similar problems up to then. Then, a comparison with the state-of-the-art is possible. We like to remark that Codd's $(1970,1982)$ theory has never been explicated as a design theory by Codd; but it was reconstructed, e.g., by Walls et 
al. (1992) or Gregor \& Jones (2007). For comparing Codd's theory with the stateof-the-art in the 1970s, design theories for non-relational database systems at that time have to be reconstructed.

Finally, the criteria developed are based on the "ceteris paribus clause". A design theory $A$ can only be called "better" than a design theory $B$ if $A$ fulfills at least one criterion better than $B$, whereby the fulfillment of all other criteria remains equal. In practice, the ceteris paribus clause is problematic because very often one design theory will improve for some criteria and perform worse for other criteria in comparison with other design theories. The difficulties with the "ceteris paribus clause" hold true for the definition of purpose and scope. From a formal point of view, two design theories may only be compared if they address the same purpose and scope - or only those parts of the theories which share the same purpose and scope may be compared. While this condition may be fulfilled for a comparison between relational and pre-relational database models, this invariability of purpose and scope will be hard to achieve in most cases, especially for very specific design theories. On the other hand, this may encourage researchers to strive for more general design theories or mechanisms for the situational adaption of design theories.

\section{References}

Albrecht, A (1979) Measuring Application Development Productivity. In: Proc. of IBM Application Development Symp., I. B. M. Press, pp 83-92

Alter, S (2006) The Work System Method. Work System Press, Larkspur, CA

Becker, J, Niehaves, B (2007) Epistemological perspectives on IS research: a framework for analysing and systematizing epistemological assumptions. Information Systems Journal 17:197-214

Berry, D M, Tichy, W F (2003) Comments on "Formal Methods Application: An Empirical Tale of Software Development". IEEE Transactions On Software Engineering 29(6):567-571

Bird, A (2008) Thomas Kuhn. In: Zalta, E N (ed) The Stanford Encyclopedia of Philosophy

Bodart, F, Patel, A, Sim, M et al (2001) Should optional properties be used in conceptual modelling? A theory and three empirical tests. Information Systems Research 12(4):384-405

Bucher, T, Klesse, M, Kurpjuweit, S et al (2007) Situational Method Engineering - On the Differentiation of "Context" and "Project Type". In: Ralyté, J, Brinkkemper, S, Henderson-Sellers, B (ed) Situational Method Engineering - Fundamentals and Experiences, Springer, Boston, pp 33-48 Charlesworth, M J (1956) Aristotle's Razor. Philosophical Studies (Ireland) 6:105-112

Chen, P P-S (1976) The Entity-Relationship Model - Toward a Unified View of Data. ACM Transactions on Database Systems 1(1):9-36 
Codd, E F (1970) Relational Model of Data for Large Shared Data Banks. Communications of the ACM 13(6):377-387

Codd, E F (1982) Relational Database: A Practical Foundation for Productivity. Communications Of The ACM 25(2):109-117

David, M (2009) The Correspondence Theory of Truth. In: Zalta, E N (ed) The Stanford Encyclopedia of Philosophy

Devlin, B A (1997) Data Warehouse: From Architecture to Implementation. Addison Wesley, Reading et al.

Dilworth, C (2007) Scientifiic Progress. Springer, Dordrecht, NL

Dubin, R (1978) Theory Building. Free Press, New York

Feyerabend, P (1962) Explanation, Reduction, and Empiricism. In: Feigl, H, Maxwell, G (ed) Minnesota Studies in the Philosophy of Science, University of Minnesota Press, Minneapolis, pp $28-79$

Feyerabend, P (1989) Irrwege der Vernunft. Suhrkamp, Frankfurt am Main

Fitzgerald, B, Howcroft, D (1998) Competing Dichotomies in IS Research and Possible Strategies for Resolution. In: Proceedings of the International Conference on Information Systems, pp 155164

Frank, U (2006) Towards a Pluralistic Conception of Research Methods in Information Systems Research. In:

Gelernter, D H (1998) Machine Beauty: Elegance and the Heart of Technology. Perseus Books, L.L.C., New York

Gibson, M, Arnott, D (2007) The Use of Focus Groups in Design Science Research. In: Toleman, M, Cater-Steel, A, Roberts, D (ed) ACIS2007 Proceedings of the 18th Australasian Conference on Information Systems, University of Southern Queensland, Toowoomba, Australia

Goldkuhl, G (2004) Design Theories in Information Systems - A Need for Multi-Grounding. JITTA : Journal of Information Technology Theory and Application 6(2):59-72

Gregor, S (2006) The Nature of Theory in Information Systems Research. MIS Quarterly 30(3):611-642

Gregor, S (2009) Building Theory in the Sciences of the Artificial. In: Proceedings of the 4th International Conference on Design Science Research in Information Systems and Technology, ACM, New York

Gregor, S, Jones, D (2007) The Anatomy of a Design Theory. Journal of the Association for Information Systems 8(5):312-335

Habermas, J (1984) The theory of communicative action: Reason and the rationalization of society. Beacon, Boston

Hempel, C G (1962) Deductive-Nomological vs. Statistical Explanation. In: Feigl, H, Maxwell, G (ed) Minnesota Studies in the Philosophy of Science III, University of Minnesota Press, Minneapolis, pp 98-169

Hempel, C G, Oppenheim, P (1948) Studies in the Logic of Explanation. Philosophy of Science $15(2): 135-175$ 
Hevner, A R, March, S T, Park, J et al (2004) Design Science in Information Systems Research. MIS Quarterly 28(1):75-105

Inmon, W H, Strauss, D, Neushloss, G (2008) DW 2.0: The Architecture for the Next Generation of Data Warehousing. Elsevier Science, Amsterdam

Kitchenham, B, Kansala, K (1993) Inter-item correlations among function points. In: Proceedings of the First International Software Metrics Symposium 1993, IEEE Computer Society Press, Los Alamitos, CA, USA, pp 477-480

Kuechler, W, Vaishnavi, V K (2008) Theory Development in Design Science Research: Anatomy of a Research Project. In: Vaishnavi, V K, Baskerville, R (ed) Proceedings of the Third International Conference on Design Science Research in Information Systems and Technology, pp 1-15 Kuechler, W, Vaishnavi, V K, Kuechler Sr, W L (2007) Design [Science] Research in IS - A Work in Progress. In: Proceedings of the Second International Conference on Design Science Research in Information Systems and Technology (DESRIST 2007), pp 1-17

Kuhn, T S (1970) The Structure of Scientific Revolutions. Chicago University Press, Chicago

Kuhn, T S (1977) The Essential Tension. Selected Studies in Scientific Tradition and Change. University of Chicago Press, Chicago

Lee, A S (1991) Architecture as a Reference Discipline for MIS. In: Nissen, H E, Klein, H K, Hirschheim, R (ed) Information Systems Research: Contemporary Approaches and Emergent Traditions, North-Holland, Amsterdam et al., pp 573-592

Lee, A S (1999) Inaugural Editor's Comments. MIS Quarterly 23(1):v-xi

Losee, J (2004) Theories of Scientific Progress. An Introduction. Routledge, New York, London March, S T, Smith, G F (1995) Design and Natural Science Research on Information Technology. Decision Support Systems 15(4):251-266

Markus, M L, Majchrzak, A, Gasser, L (2002) A Design Theory for Systems that Support Emergent Knowledge Processes. MIS Quarterly 26(3):179-212

Michaels, A S, Mittman, B, Carlson, C R (1976) A Comparison of the Relational and CODASYL Approaches to Data-Base Management. Computing Surveys 8(1):125-151

Nagel, E (1961) The Structure of Science. Harcourt, Brace \& World, New York

Niehaves, B (2007a) On Epistemological Diversity in Design Science: New Vistas for a DesignOriented IS Research? In: Proceedings of the 28th International Conference on Information Systems (ICIS2007), Dec 9-12, 2007, Montréal, Québec, Canada, Association for Information Systems (AIS), pp 1-13 (electronic version)

Niehaves, B (2007b) On Epistemological Pluralism in Design Science. Scandinavian Journal of Information Systems 19(2):93-104

Niiniluoto, I (2007) Scientific Progress. In: Zalta, E N (ed) The Stanford Encyclopedia of Philosophy

Norman, D (1988) The Design of Everyday Things. Currency Doubleday, New York

Peffers, K, Tuunanen, T, Gengler, C E et al (2006) The Design Science Research Process: A Model for Producing and Presenting Information Systems Research. In: Chatterjee, S, Hevner, A (ed) Proceedings of the First International Conference on Design Science Research in Information Systems and Technology (DESRIST 2006), pp 83-106 
Peffers, K, Tuunanen, T, Rothenberger, M A et al (2007) A Design Science Research Methodology for Information Systems Research. Journal of Management Information Systems 24(3):45-77

Popper, K R (1963) Conjecture and Refutations. Oxford University Press, Oxford

Popper, K R (1973) The Aim of Science. In: Popper, K R (ed) Objective Knowledge (with corrections), Oxford University Press, Oxford

Purao, S (2002) Design Research in the Technology of Information Systems: Truth or Dare. In, Atlanta, GA

Rossi, M, Sein, M K (2003) Design Research Workshop: A Proactive Research Approach. http://tiesrv.hkkk.fi/iris26/presentation/workshop_designRes.pdf. Accessed 19 Sep 2008

Simon, H A (1996) The Sciences of the Artificial. MIT Press, Cambridge, London

Sobel, K A E, Clarkson, M R (2002) Formal methods application: An empirical tale of software development. IEEE Transactions On Software Engineering 28(3):308-320

Sobel, K A E, Clarkson, M R (2003) Response to "Comments on 'Formal Methods Application: An Empirical Tale of Software Development'". IEEE Transactions On Software Engineering 29(6):572-575

Venable, J (2006a) A Framework for Design Science Research Activities. In: Emerging Trends and Challenges in Information Technology Management, Idea Group Publishing, Hershey etc., pp 184-187

Venable, J (2006b) The Role of Theory and Theorising in Design Science Research. In: Chatterjee, S, Hevner, A (ed) Proceedings of the 1st International Conference on Design Science in Information Systems and Technology (DESRIST 2006), Claremont Graduate University, Claremont, CA, pp 1-18

w/o author (1989) simple. In: Simpson, J, Weiner, E (ed) Oxford English Dictionary, 2, Oxford University Press

Walls, J G, Widmeyer, G R, El Sawy, O A (1992) Building an Information System Design Theory for Vigilant EIS. Information Systems Research 3(1):36-59

Walls, J G, Widmeyer, G R, El Sawy, O A (2004) Assessing Information Systems Design Theory in Perspective: How Useful was our 1992 Initial Rendition? Journal of Information Technology Theory and Application 6(2):43-58

Young, J O (2008) The Correspondence Theory of Truth. In: Zalta, E N (ed) The Stanford Encyclopedia of Philosophy 